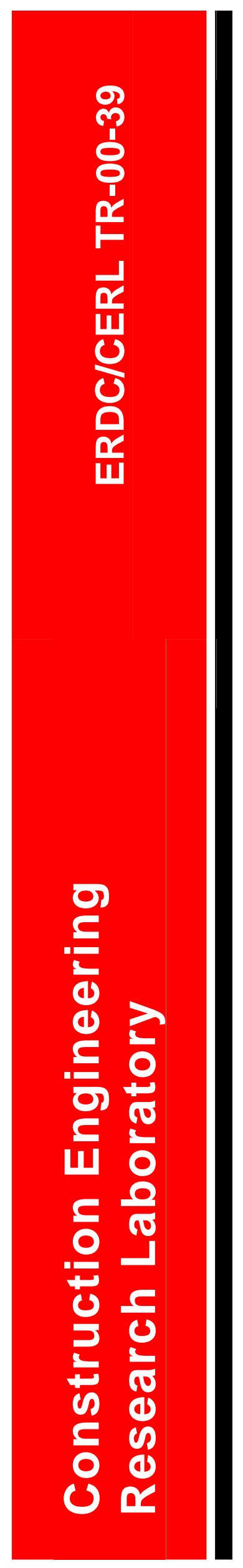

\title{
Scoping Report for a Scenario-Based Planning Protocol for Application in the Regions of Army Installations
}

Winifred H. Rose, Robert C. Lozar, and Richard L. Schneider

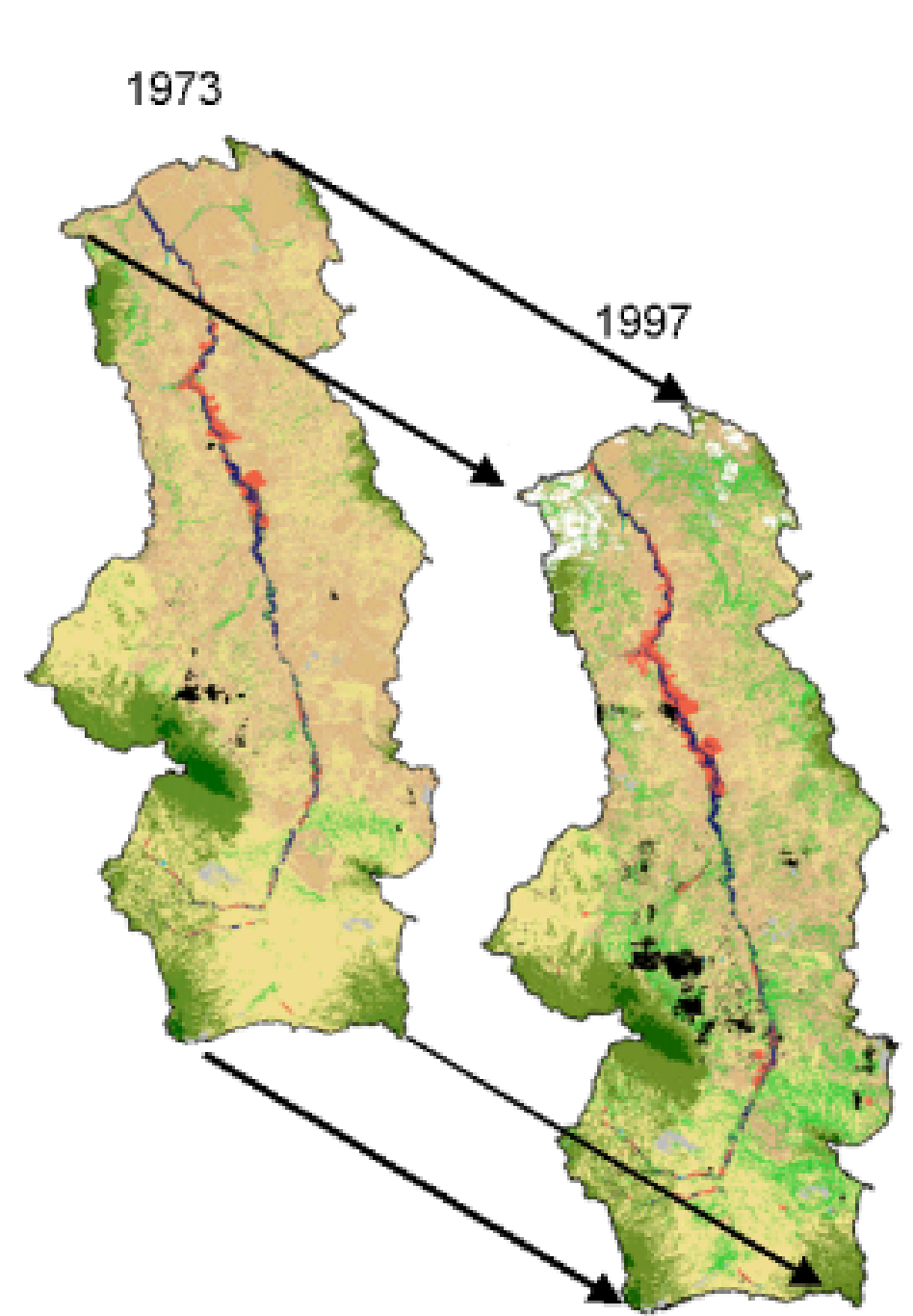




\section{Foreword}

This study was conducted for U.S. Army Corps of Engineers under A896 "Scenario-Based Land Management," T79 and T70, "Scenario-Based Regional Land Management Planning for Military Installations." The technical monitor was Dr. William D. Severinghaus, CEERD-CVT.

The work was performed by the Land and Heritage Conservation Branch (CN-C) of the Installations Division (CN), Construction Engineering Research Laboratory (CERL). The CERL Principal Investigators were Ms. Winifred Hodge Rose and Mr. Robert C. Lozar. The technical editor was Gloria J . Wienke, Information Technology Laboratory. Mr. Robert E. Riggins is Chief, CEERD-CN-C, and Dr. J ohn T. Bandy is Chief, CEERD-CN. The associated Technical Director was Dr. William D. Severinghaus, CEERD-CVT. The Acting Director of CERL is Dr. William D. Goran.

CERL is an element of the U.S. Army Engineer Research and Development Center (ERDC), U.S. Army Corps of Engineers. The Director of ERDC is Dr. J ames R. Houston and the Commander is COL J ames S. Weller.

\section{DISCLAIMER}

The contents of this report are not to be used for advertising, publication, or promotional purposes. Citation of trade names does not constitute an official endorsement or approval of the use of such commercial products. All product names and trademarks cited are the property of their respective owners.

The findings of this report are not to be construed as an official Department of the Army position unless so designated by other authorized documents.

DESTROY THIS REPORT WHEN IT IS NO LONGER NEEDED. DO NOT RETURN IT TO THE ORIGINATOR. 


\section{Contents}

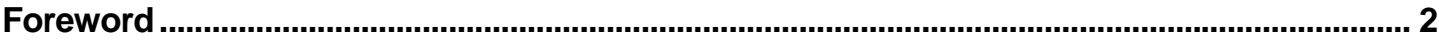

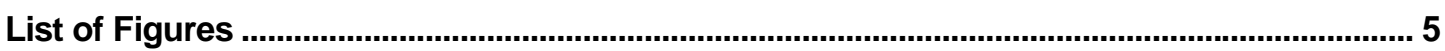

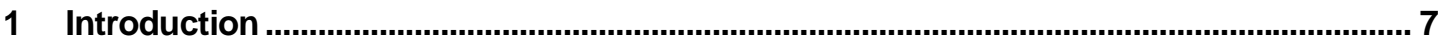

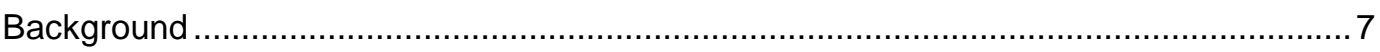

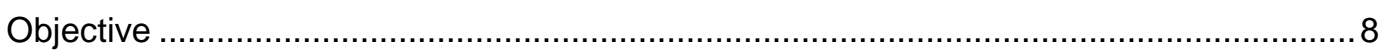

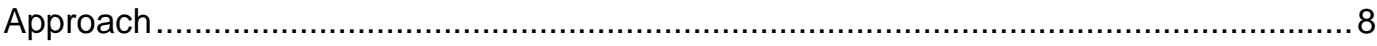

Scope

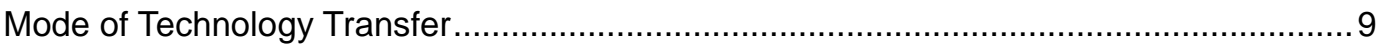

2 The Basis for a Regional Scenario-Based Land Use Planning Protocol ........................ 10

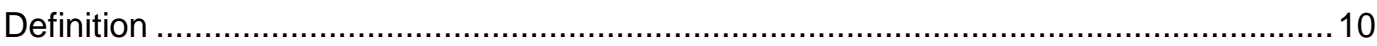

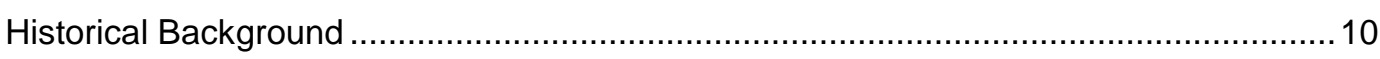

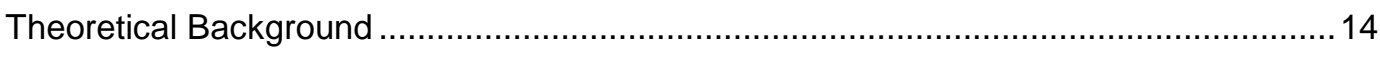

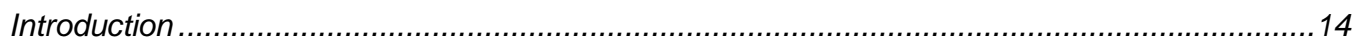

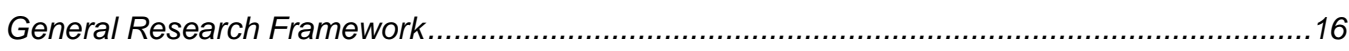

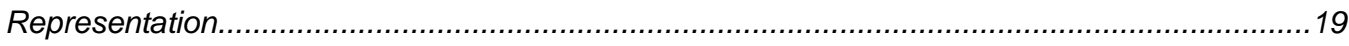

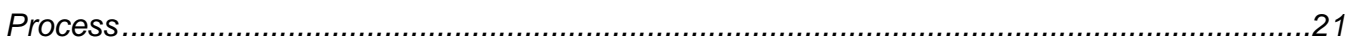

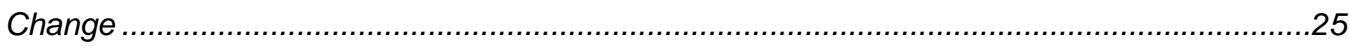

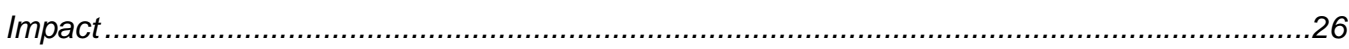

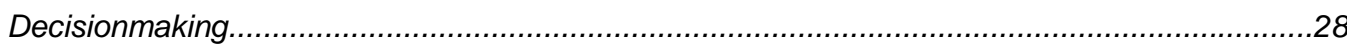

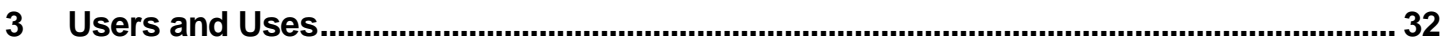

Why and How to Adapt Regional Scenario-Based Planning for Military Use ....................32

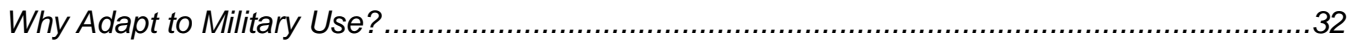

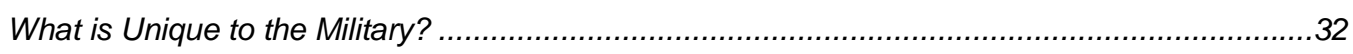

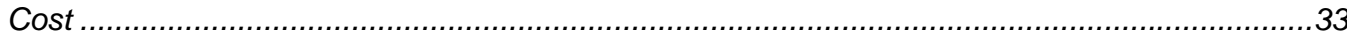

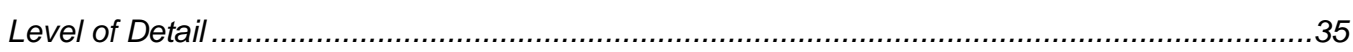

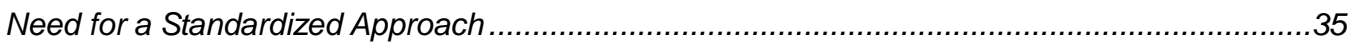

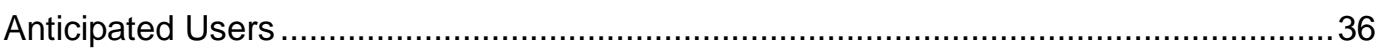

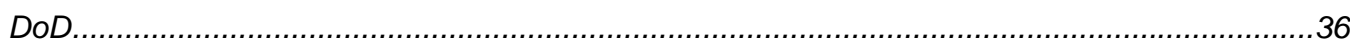

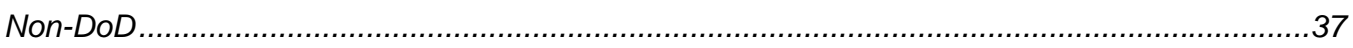

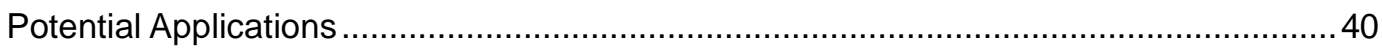

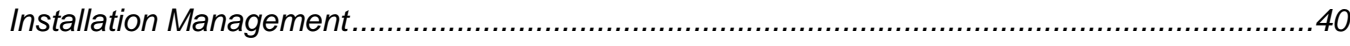

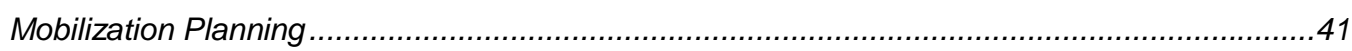




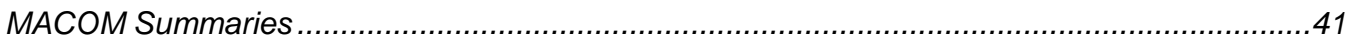

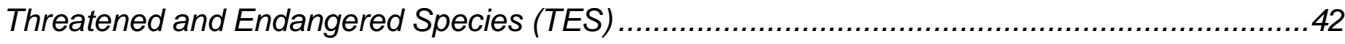

Natural and Cultural Resources Management ............................................................43

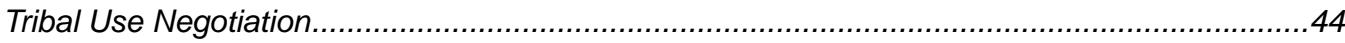

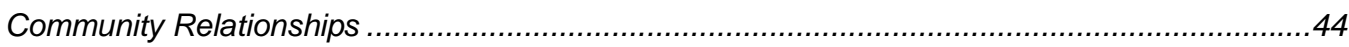

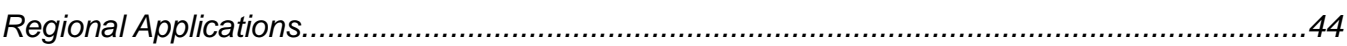

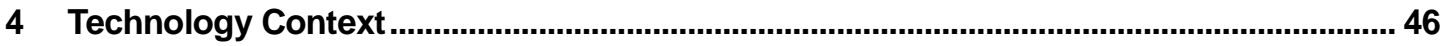

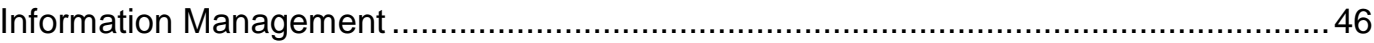

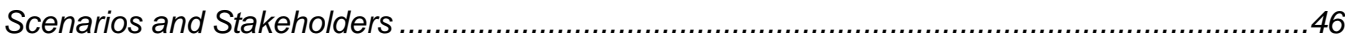

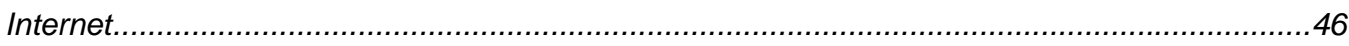

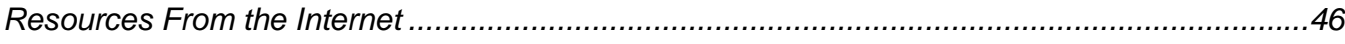

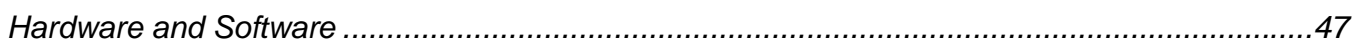

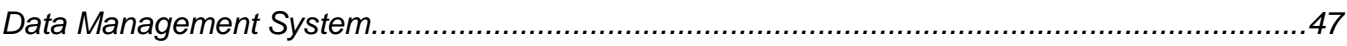

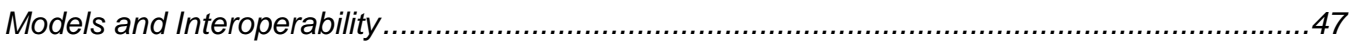

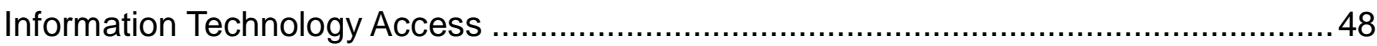

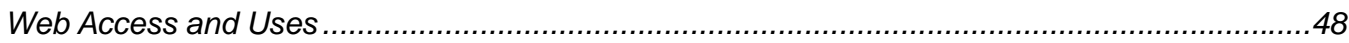

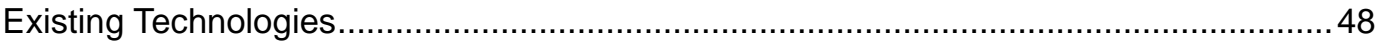

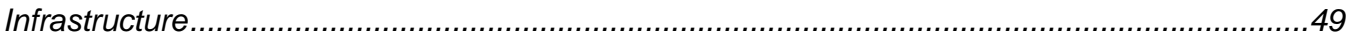

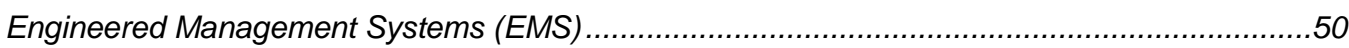

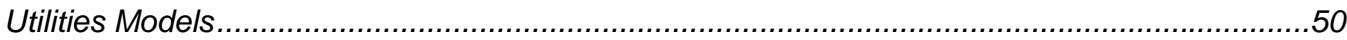

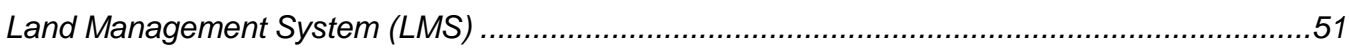

Army Training and Testing Area Carrying Capacity (ATTACC) ..........................................51

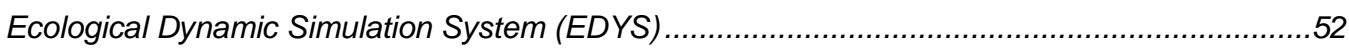

Military Ecological Risk Assessment Framework (MERAF) .................................................5

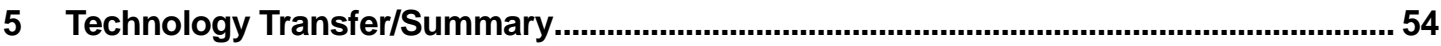

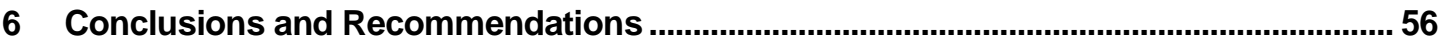

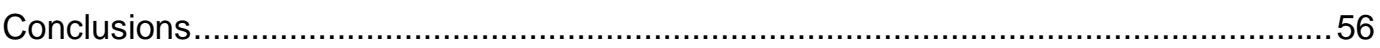

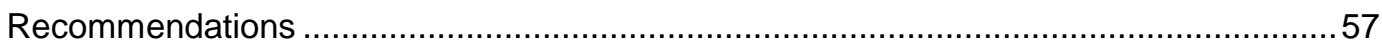

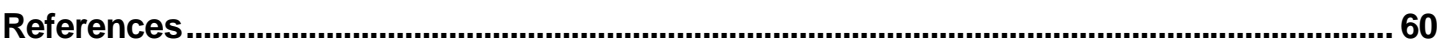

Appendix A: $\quad$ Web Materials Search Bibliography .......................................................... 61

Appendix B: $\quad$ APA List of Accredited American University Planning Programs ............ 67

CERL Distribution .............................................................................................................. 76

Report Documentation Page ................................................................................................... 77 


\section{List of Figures}

\section{Figures}

1 Generalized diagram of a military installation and its regional context. ....................15

2 General framework for scenario-based planning. ................................................ 17

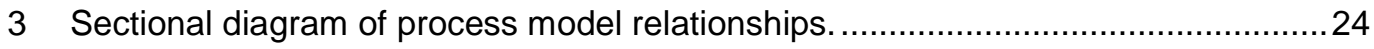

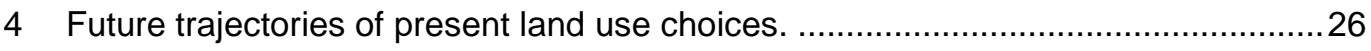

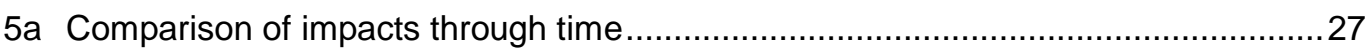

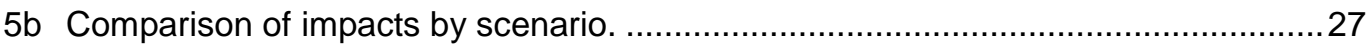

6 Example decision matrix for choosing a scenario................................................29 



\section{Introduction}

\section{Background}

Military installations across the United States are experiencing a number of pressing, complex, and interrelated challenges related to natural resources and natural resource management issues both on and off the installation. Demands of the military mission are often seen as competing or conflicting with the interests of management boards, planning organizations, and other interest groups. In some areas of the United States, conflicts have arisen over: water rights, water recharge, surface and subsurface hydrology, and critical habitat management for endangered species; military lands/missions impact on biodiversity, aesthetics, and recreational value, and on endangered species; and cumulative impact or regional development issues. It should be noted that all these issues are closely related and will require an interdisciplinary and integrated planning approach for long-term management.

Within the past 5 years, several examples of alternative futures or scenariobased regional planning have been applied to military installations: at Camp Pendleton Marine Corps Base, CA; within the Fort Huachuca region, AZ; and at several installations in the Mojave Desert region. Alternative approaches and scenario-based planning show promise for the Army and Department of Defense (DoD) in helping avoid and resolve issues related to encroachment and other re gional issues that concern both military installations and their neighbors. The ad hoc application of scenario-based planning to individual installations has resulted in a good but expensive technical information product (report on planning scenarios). The product has not necessarily resulted in the transfer of scenariobased planning tools for future installation use. There is a need to find and apply less expensive, more generic and standardized approaches for scenario-based regional planning in a way that gives installations and/or DoD centers of expertise the necessary tools for future applications of the technology.

Military installations need a regional-scale, ecosystem-based, integrated, longterm planning approach or methodology. Two projects that demonstrate such an approach have taken place at Camp Pendleton, CA, and in the San Pedro river basin in Arizona and Mexico, which includes Fort Huachuca, AZ. 
A prototype demonstration of a regional scenario-based analysis and planning approach at Camp Pendleton, CA, was completed in 1996 by the Environmental Protection Agency (EPA)-led Biodiversity Research Consortium and Harvard University. This approach emphasized:

- close coordination and cooperation with regional stakeholders in the area surrounding the installation;

- a strongly interdisciplinary approach that includes both natural and social sciences; and

- a flexible and practical planning approach that facilitates cooperative decisionmaking in a regional context.

The San Pedro project is providing information for:

- executing long-term environmental planning conjointly between Fort Huachuca, their neighboring landowners, and other regional stakeholders in the United States and Mexico;

- addressing identified shortcomings in cumulative impact analysis and other proactive planning needs;

- identifying and evaluating installation-level and regional ecosystem and water management options; and

- selecting an optimal ecosystem management plan based on these analyses and requirements.

Scenario-based regional planning methodology, appropriately adapted, is expected to prove very suitable for application to the challenges facing United States military installations.

\section{Objective}

The objective of this work is to describe a regional scenario-based land use planning methodology, and explore how a standardized protocol for comprehensive military land use planning in a regional context could be developed and applied.

\section{Approach}

The first phase in this research is to conduct a scoping study that describes regional scenario-based planning methodology, evaluates its potential for application to military land use planning, and presents characteristics and criteria for development of a generalized scenario-based planning protocol adapted for military use. The second phase, which will be presented in a separate document, will provide a review and analysis of existing software and other resources for 
scenario-based planning, apply one selected software tool to a military installation using existing data, and recommend modifications to this approach for better Army application.

\section{Scope}

This report constitutes a scoping study for the potential application of scenariobased planning to any military land management and planning.

\section{Mode of Technology Transfer}

Information in this report is being presented to the Engineer Research and Devel opment Center (ERDC) Technical Directors office for presentation to and discussion with installation and major command (MACOM) customers. 


\section{The Basis for a Regional Scenario- Based Land Use Planning Protocol}

\section{Definition}

The planning protocol is a systematic procedure for conducting scenario-based analyses of potential futures at a regional scale. The changes being tracked are based on the common denominator of land use type. Land use types are spread over a region. Over time, land use distribution changes based on:

1. Likely or desired planning incentives and restrictions,

2. Land use suitabilities for a specific location, and

3. Land use impact that can influence changes occurring during the next increment of time.

Land use types are stored and manipulated in a computer readable grid in a standard Geographical I nformation System (GIS) format.

\section{Historical Background}

The idea of generating alternative land use distributions and impacts over an extended time horizon has a long history. Dr. Carl Steinitz developed the initial class workshop in 1968 in a Harvard University program, the results of which were later published (Steinitz 1967).

Over the intervening 30 years, the technology used to carry out these concepts has become highly sophisticated and encompassing. However, the basic concept has remained the same. In simplest terms, a land use has both suitability and an impact on the area around it. Land use is modified by different "Planning Incentives." Remember that natural land is a land use.

As development occurs, natural land either changes or remains the same, based on how suitable it is for industry, transportation, residential, and commercial uses. That change over time then changes the land's suitability for the new land use, and more importantly, affects the suitability of the nearby areas for a particular land use. As examples, a natural area changing to a highway may attract 
industry that attracts residential development nearby. Later, the residential land use attracts supporting commercial land uses, which then cause a demand for more residential area. This dynamic can be tracked over time.

Professor Steinitz's great innovation was to assign numeric values of suitability ("attractiveness") to each cell within a grid of cells covering the regional study area. By this method, a software program can calculate how the attractiveness of each cell for land use of a particular type would reasonably change over a time increment (say over 5 years). This can then be repeated over the next time increments as far into the future as one may be willing to believe in the results (usually in the range of 25 to 40 years). It would be unreasonable to think that a particular land use would be in the predicted cell 25 years into the future. However, it would be entirely reasonable to think that within the entire region, the mixture of land uses and their generalized distribution would be appropriate for the change dynamics that would occur within the entire region. Thus, the outline of the future development of a region could be predicted, though the specifics would be more difficult to identify. For planning purposes, this process would be entirely adequate.

Second, in addition to the attractiveness of a location, or GIS cell, each cell can also carry metrics of environmental and social impact. Impacts can impinge on water quality, air quality, soil erosion, biodiversity, degree of open space, visual appeal, and overall quality of life. Each cell can be assigned numeric values reflecting the degree of impact in each concern. This provides a "report card" on what was happening over time within a cell, but more importantly, a review of all the cells provides a summary over the entire the region. These numeric impacts also influence the locations' basic land use attractiveness. Thus, change at each increment would result in an impact score and an influence on the future.

Third, the dynamic of change can be moderated by the planning "incentives" or land-use restrictions assigned during planning scenarios. That is, the alternative future chosen would influence the attractiveness of the cell for each land use. One could choose a "conservation" scenario, which would decrease the attractiveness of cells for development. At the other extreme, one could choose a "development" scenario, which would cause the region to become built up much more quickly and thus affect conservation values. Thus, scenario-based planning can assist individuals and agencies to more clearly understand and influence local destinies.

These concepts have been applied in numerous studies. One recent report is the Alternative F utures in the Western Galilee, Israel, edited by Carl Steinitz. This is a study of urban growth and change in the Western Galilee region of Israel. The 
summary of findings presents issues, planning strategies, and design proposals, and is available on the web at: http://www.gsd.harvard.edu/publications/galilee.htm.

Another study is the Alternative Futures for Monroe County, Pennsylvania, led by Carl Steinitz and published in 1994. Much of the initial understanding about the County came from published reports about the area including Township and County planning documents, tourism pamphlets, and nature guidebooks. It quickly became clear that any important decision concerning the future of Monroe County would involve a wide range of issues and decision criteria that can be summarized as the interaction between future urbanization and the geologic landscape, the biologic landscape, and the visual landscape, influenced by demographics, economics, and politics. The study, therefore, focused on these issues, which shape landscape planning decisions in Monroe County.

One recent study for the military was concluded at Camp Pendleton Marine Corps Base, CA, in 1996. The study, Landscape Planning for Biodiversity: Alternative Futures for the Region of Camp Pendleton, CA (Steinitz et al. 1996) was organized to show urban growth and change forecast for the next 20 years in the region of Camp Pendleton (a rapidly urbanizing area between San Diego and Los Angeles). The changes will influence both the current biodiversity of that area and the habitat conditions present on the Camp property. The research speculates on the impacts of the continuation of these trends to a 40-year horizon. This study can be found on the web at: http://www.gsd.harvard.edu/brc/brc.html.

The objectives of the study were:

1. To forecast land-use changes in the Camp Pendleton region based on existing plans developed by regional and country planning agencies.

2. To simulate the relationships between land use, hydrological regime, and re gional biodiversity in order to evaluate these impacts.

3. To develop alternative regional change patterns with conservation of biodiversity as the primary objective, and more traditional planning objectives as secondary objectives.

4. To evaluate and compare the predicted impacts of the alternative plans on biodiversity by using the models developed in objective 2 .

5. To devise mitigating land-use planning strategies for the context region and for individual sites on Camp Pendleton.

The study was organized at three geographic scales:

1. The context region of Camp Pendleton, defined as the area that includes the watersheds of the San J uan, San Mateo, Santa Margarita, and San Luis Rey Rivers;

2. The property boundary of Camp Pendleton, and; 
3. Specific habitat zones within Camp Pendleton of known rare and endangered species.

I mpacts on biodiversity are triggered in two ways. One is related to the locations of new development and is caused by deforestation, grading, paving, and associated maintenance and use. The second is the indirect effects of the secondary and cumulative effects of development. These are simulated by the influence of hydrology changes on vegetation and, consequently, on habitat.

For the indirect effects, the study presumes the working hypothesis that hydrological regime (i.e., the amount, timing, location, and quality of available surface water, soil water, and groundwater) is a major factor controlling biodiversity in Southern California. It is the contention of the study that the relationship between vertebrate species richness and potential evapotranspiration at a large scale described by Currie (1991) is best interpreted for smaller areas as a measure of soil water deficit or hydroperiod (i.e., inundation duration) (Stephenson 1990). Water availability controls edaphic factors for plant communities, which in turn provide habitat for animals. Any alterations to the hydrological regime will necessarily affect biodiversity, often in places distant from the source of the alteration.

The major stressors that cause biodiversity change are hypothesized to be urbanization-related "development" in the context region and construction, maintenance, and use plans and practices at Camp Pendleton. As development spreads, habitat is lost first. Consequently, the hydrological regime will be altered to one of shorter and more intense floods, but with lower streamflow and lower available soil moisture most of the year. And habitats will change in ways we can begin to model. Predicted habitat changes due to different development scenarios are used to assess the relative desirability of various scenarios in terms of biodiversity maintenance, and may be used to devise more appropriate regional policies and plans.

The Pendleton study had three phases. The first phase was devoted to collecting, integrating, reconciling, and in some cases digitizing necessary base data. Data sources included the two important regional planning agencies (San Diego Association of Governments [SANDAG] and Southern California Association of Governments [SCAG]), the U.S. Marine Corps, interested conservation groups including The Nature Conservancy, and others. The present working database is maintained in Arc/l nfo, primarily in raster GRID format at a 30M-cell resolution, and comprises about 10 gigabytes of data. 
The second phase focused on developing a suite of single-species habitat preference models, based on biological literature and primarily using vegetation, hydrology, elevation, and land use data. In addition, more aggregate statistical GAP analysis and species richness analysis were performed by researchers at Utah State University.

The third phase concentrated on planning and management strategies to mitigate the (expected) impacts on biodiversity. Alternative scenarios, devised with the objective of maintaining or enhancing biodiversity relative to current trends, were developed and tested during this phase. Four principal alternative scenarios were considered: (1) uncontrolled growth according to present plans, (2) a multi-purpose conservation oriented plan, (3) a single-center growth plan, and (4) a multi-center growth plan. These latter were devised by graduate students in a regional planning studio at the Graduate School of Design under Professor Steinitz's direction.

\section{Theoretical Background}

\section{Introduction}

A regional scenario-based planning study is designed with two objectives:

1. To develop an array of plausible alternative future patterns of land uses for a region and

2. To assess the resultant impacts these scenarios might have on land use patterns.

This generalized alternative futures protocol can be applied to any DoD facility.

A basic premise of this research is that issues related to strategic land use and ecosystem management from the viewpoint of a military installation can be best undertaken at a regional scale. This normally means that the watershed or other driving factor (e.g., the economic region or the soil resource unit) of primary concern plus adjacent areas essential to capture the regional context need to be included. Figure 1 illustrates how a military installation fits into the larger surrounding contexts, all of which influence and are influenced by regional land uses.

Issues of concern for the region must be identified. These issues include the driving economic, demographic, natural resource, political, biological, hydrologic, and development issues that can be predicted to be of major concern within the near planning horizon (e.g., the next 5 years) and those that will continue to be or can be reasonably predicted to emerge in the more distant planning horizon 
(e.g., from 5 to 50 years). It is clear that predictions are more reliable in the shorter time frame.

The purpose of this work is to follow in a logical process the dynamics of the decisions that might be made now, and see the likely effects those will generate in decades to come. Failing to plan responsibly forces one to accept the results of decisions made under immediate pressures of the day, to the possible detriment of future generations. This is not to say that participants must actively desire the futures they chose to create; often an analysis will show unexpected and undesirable outcomes resulting from present decisions thought to be beneficial. Scenario-based planning helps ensure that all people involved are aware of the likely ramifications of present-day decisionmaking. The military and other regional stakeholders need to know the extent to which future land use patterns are likely to impact the regional landscape, in ways that could profoundly affect execution of the military mission.

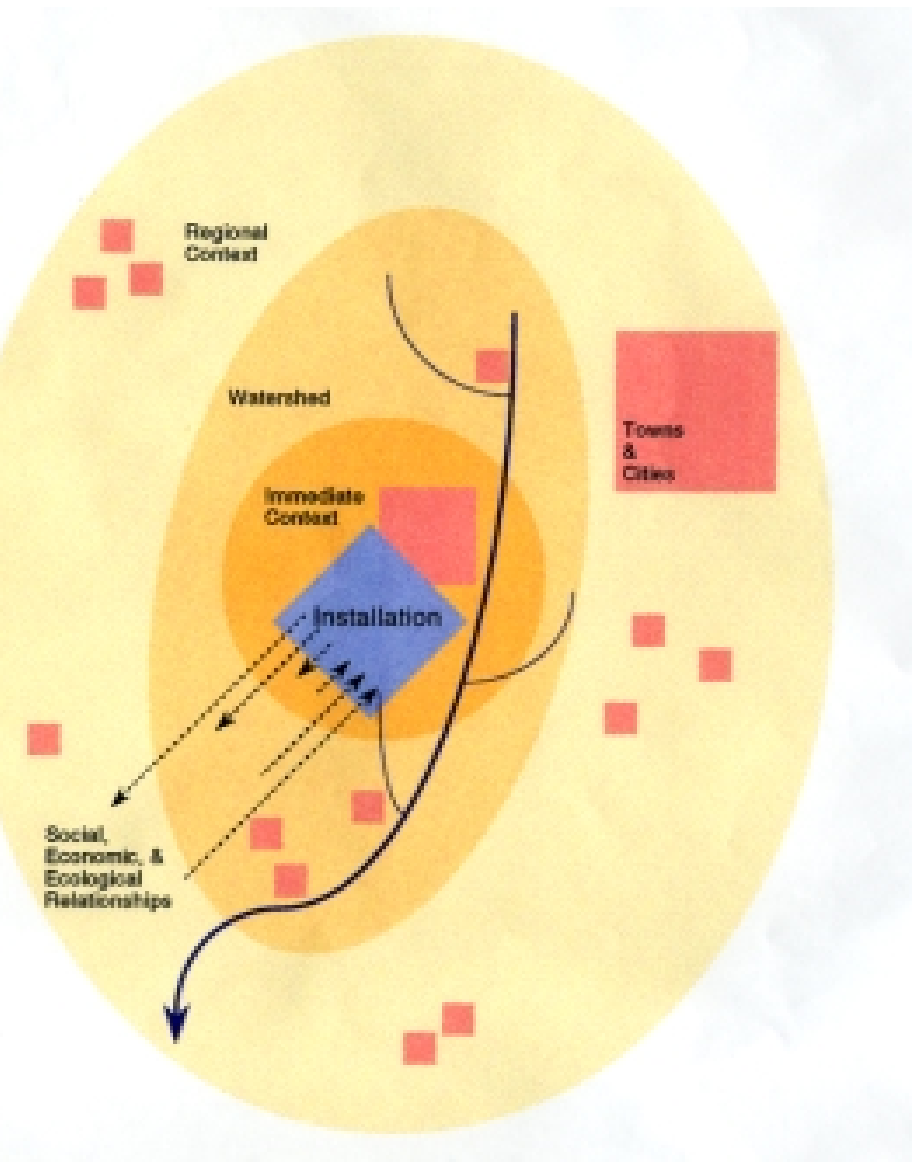

Figure 1. Generalized diagram of a military installation and its regional context.

(From: Poster presented at the 1998 SERDP Symposium, entitled Alternative Futures for the Upper San Pedro River Basin, Arizona and Sonora: The Region of Fort Huachuca, describing work funded by the DoD Legacy Program and conducted by the Harvard Design School, ERDC/CERL, U.S. Army TRADOC, the Desert Research Institute, the University of Arizona, and the Semi-Arid Land Surface/Atmosphere [SALSA] program.) 
Issues are usually closely related and require a multi-disciplinary and integrated planning approach for long-term management. Most installations will need a regional-scale, ecosystem-based, long-term planning approach to encompass the necessary breadth and depth of land use issues.

One requirement when undertaking any scenario-based planning is to bring together all the stakeholders within a region, to the extent possible. This can occur in many contexts, including having the local installation and perhaps also its MACOM participate in existing regional planning efforts and studies, as well as proposing and participating in new joint efforts. By working in a collaborative rather than confrontational environment, the installation builds trust and understanding of its interests in the region. Representation of military land uses and interests in regional land use planning efforts ensures that the military mission is taken into account when providing a broadly based set of alternatives for the area. Collaboration also helps to avoid unpleasant and expensive surprises that can occur when military and civilian land use decisions are pursued without reference to one another. Such lack of coordination can have serious consequences on the long-term sustainability and political viability of the military mission in the region.

\section{General Research Framework}

The general research framework discussed here is excerpted from the work of Dr. Carl Steinitz and associates (1996), as presented in Biodiversity and Landscape Planning: Alternative Futures for the Region of Camp Pendleton, CA.

The framework shown in Figure 2 identifies six different questions, each of which is related to a model or answer. The framework is "passed through" at least three times in any project:

1. downward in identifying the context and scope of the study - defining the questions;

2. upward in specifying the methods of study - deciding how to answer the questions; and

3. downward in carrying the study to its condusion - providing the answers. 


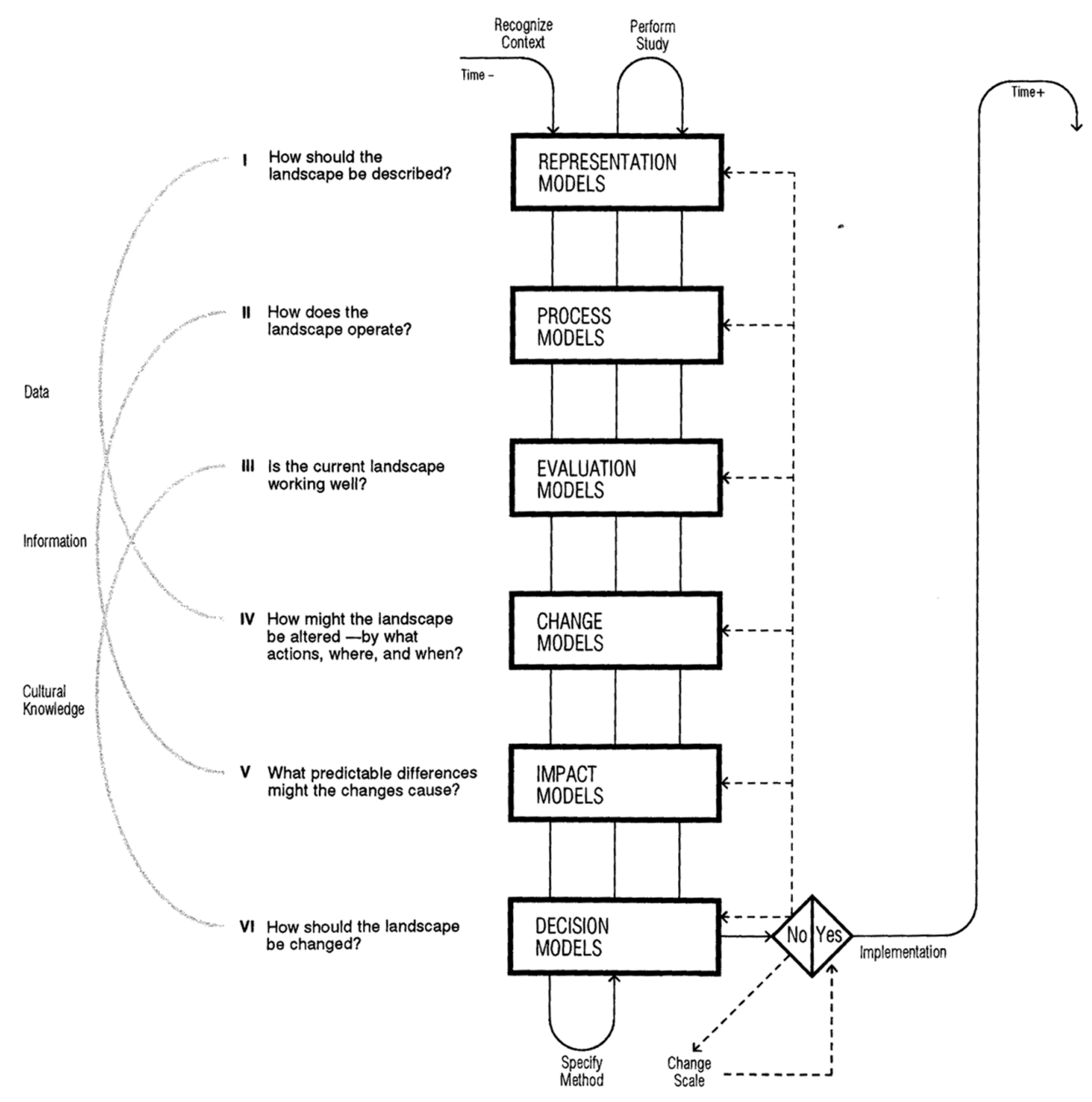

Figure 2. General framework for scenario-based planning.

(From: Figure 5, p 6, in Biodiversity and Landscape Planning: Alternative Futures for the Region of Camp Pendleton, CA, by Carl Steinitz et al., under work funded by the DoD/DOE/EPA Strategic Environmental Research and Development Program.)

The six questions with their associated modeling types are listed in the order in which they are usually considered when initially defining a design study.

I How should the state of the landscape be described; in content, boundaries, space, and time? This level of inquiry leads to Representation Models.

II How does the landscape operate? What are the functional and structural relationships among its elements? This level of inquiry leads to Process Models. 
III Is the current landscape functioning well? The metrics of judgment (whether of environmental health, beauty, cost, nutrient flow, or user satisfaction) lead to Evaluation Models.

IV How might the landscape be altered; by what actions, where, and when? This is directly related to the Representation Models in that both are data: vocabulary and syntax. This fourth level of inquiry leads to Change Models. At least two important types of change should be considered: change by current projected trends, and change by implementable design, such as plans, investments, and regulations.

V What predictable differences might the changes cause? This is directly related to Process Models in that both are based on information; on predictive theory. This fifth level of inquiry shapes I mpact Models, in which the Process Models are used to simulate change.

VI Should the landscape be changed? How is a comparative evaluation among the impacts of alternative changes to be made? This is directly related to Evaluation Models in that both are based on knowledge; on cultural values. This sixth level of inquiry leads to Decision Models.

Implementation should be considered another level, but this framework considers it as a forward-in-time feedback to Level I, the creation of a changed representation model.

Note that the six levels have been presented in the order in which they are normally recognized. However, it is more important to consider them in reverse order as a more effective way of both organizing a landscape study and specifying its methods. The methods should be organized and specified upward through the levels of inquiry, with each level defining its necessary contributing products from the models next above in the framework.

To be able to decide to make a change or not (Step VI), one needs to know how to compare alternatives. To be able to compare alternatives, one needs to predict their impacts from having simulated changes (Step V). To be able to simulate change, one needs to specify (or design) the changes to be simulated (Step IV). To be able to specify potential changes (if any) one needs to evaluate the current conditions (Step III). To be able to evaluate the landscape, one needs to understand how it works as processes (Step II). And to understand how it works, one needs representational schema to describe it (Step I). 
Then, to be effective and efficient, a landscape project should also progress downward at least once through each level of inquiry, applying the appropriate modeling types.

At the extreme, two decisions present themselves: "no" and "yes." A "no" implies a backward feedback loop and the need to alter a prior level. All six levels can be the focus of feedback; "redesign" (Step IV) is a frequently applied feedback strategy. A "contingent yes" decision (still a "no") may also trigger a shift in the scale or size or time of the study. (An example is a change in a highway corridor location decision made on the basis of a more detailed alignment analysis.) In a scale shift, the study will again proceed through the six levels of the framework, as previously described.

A project should normally continue until it achieves a positive "yes" decision. A "yes" decision implies implementation and (one assumes) a forward-in-time change to new representation models.

While the framework and its set of questions and models looks orderly and sequential, it frequently is not so in its application. The line through any project is not a smooth path; it has false starts, dead ends, and serendipitous discoveries. But activities do pass through the questions and models of the framework as described, before a "yes" can be achieved.

\section{Representation}

To create models that simulate how the landscape operates, it is necessary to have a representation of the landscape. Examples of needed data are listed below, as developed by the Harvard Design School for the multi-agency alternative futures study of the San Pedro River Basin/F ort Huachuca region in Arizona and Mexico (publication forthcoming).

\section{Population Allocation}

- Population forecasts

- Demographic forecasts

\section{Historic and Cultural Resources}

- Identification of significant periods, areas

- Locations of areas of historic interest

- These places may also need to be (should be) classified by type (e.g., historic ranch, monument, battlefield, etc.) and by date

- Maps of archaeological sites 


\section{Visual Quality}

- Digital Elevation Model

- Land Cover

- Identification of important viewing locations such as designated overlooks in parks and from major roads

- Survey information on how residents evaluate beautiful scenery

- Survey information on how tourists evaluate beautiful scenery

\section{Traffic}

- Road network capacity and current traffic levels

- Location of new roads or proposed road upgrades

- Expectations of driving distances for work, recreation, etc

- Average vehicle miles traveled per person per day

\section{Land Value}

- Point or parcel information on real estate transactions

- Information on the location of "improved" parcels-those with electricity, water, and road access

- Land values from the assessor's office and the multipliers for assessed vs. actual value

\section{Fire}

- Fire history atlas, or fire return interval data by vegetation class and topographic position

- Vegetation with relationships to fuel types

- Fuels information showing quantity and structure of fuels

- Climate records and model, showing temperature, humidity and precipitation

- Digital Elevation Model, from which slope, aspect, and el evation (major fire risk components) are derived

\section{Precipitation, Surface Water Runoff, and Infiltration}

- Historic patterns of storm events, probably the 2-year storm

- Land use coverage recoded for run-off coefficients

- Soils map coded for hydrol ogic soils groups

- Terrain.

\section{Soil Moisture}

- Land cover

- Evapotranspiration rates 
- Solar exposure and other climatic data

- Average (seasonal) wind speed and direction

- Terrain

- Run-off curve number

\section{Ground Water}

- Precipitation records

- Data from river gauging stations

- Data or estimates of well water pumped from the aquifer

- Evapotranspiration rates for riparian plant communities

- Stream morphology and subsurface geology

\section{Vegetation Dynamics}

- Urban and exurban stressors from the scenarios

- Fire model output

- Soil moisture output

- Grazing practices (handled as a function of land use)

- Climate

- Vegetation management (foresting, grazing, etc.)

- Flood related activities

\section{Landscape Ecology}

- Land cover recoded into natural vegetation, "disturbed" vegetation (including agriculture), and urban areas

\section{Species Richness}

- Vegetation requirements

- Land protection classifications

- Land cover and vegetation

\section{Process}

To evaluate how well the landscape is working, it is necessary to understand how the landscape operates. Following is the list of the objectives of the process models developed for the multi-agency alternative futures study of the San Pedro River Basin/Fort Huachuca region (publication forthcoming).

\section{Population Allocation}

- To estimate population change within the region.

- To identify allowable (or preferred) housing densities. 


\section{Historic and Cultural Resources}

- To identify areas of current historical or other culturally significant importance toward the creation of a map of points, routes, and areas that may be conserved.

\section{Visual Quality}

- To identify areas of scenic beauty in terms of preferences expressed by both residents and by tourists.

\section{Traffic}

- To quantify the change in expected traffic volume on existing major roads in the area.

\section{Land Value}

- To estimate the cost of implementing infrastructure improvements and conservation initiatives in alternative future scenarios.

\section{Fire}

- To prioritize areas where prescribed burning would be of high ecological importance and politically and administratively possible now, or in the future.

\section{Precipitation, Surface Water Runoff, and Infiltration}

- To estimate water input into the hydrologic regime.

- To quantify the change in run-off caused by development and vegetation management.

\section{Soil Moisture}

- To quantify changes in soil moisture caused by changes in land use. If soil moisture can be correl ated to vegetation types then showing expected changes in soil moisture can serve as one measure of risk to vegetation brought on by urbanization.

\section{Ground Water}

- To provide an estimate of the base flow of a river and to describe the potential impact of flooding on the stream channel. 


\section{Vegetation Dynamics}

- To summarize of the risks to vegetation resulting from changes in land use, fire, soil moisture, and flooding.

\section{Landscape Ecology}

- To provide a qualitative measure of landscape ecological pattern.

\section{Species Richness}

- To provide a spatial representation of the diversity and variability of the vertebrate species of the area.

\section{Single Species Potential Habitat}

- To identify the habitat and other requirements for several species. Species may be selected for a number of reasons including (1) the species is listed as rare, threatened, or endangered by the State or Federal government; (2) the species is locally rare; (3) the species is a keystone indicator, so that modeling it will also capture the potential habitat of other species; (4) the species is of local sentimental or recreational importance.

Figure 3 shows a diagram of how these various processes - both natural and social - interact to shape the features of a region.

To understand what changes might be desired, it is necessary to assess how well the landscape is currently working. Such an assessment is sometimes a matter of law or regulation (for example, does water quality meet statutory requirements?) or sometimes a matter of common expectations (for example, is traffic congestion high?).

From the perspective of a DoD installation, issues related to how well the landscape is working might include the following, as presented in the poster Alternative Futures for the Upper San Pedro River Basin, Arizona and Sonora: The Re gion of Fort Huachuca (Steinitz et al. 1998). 


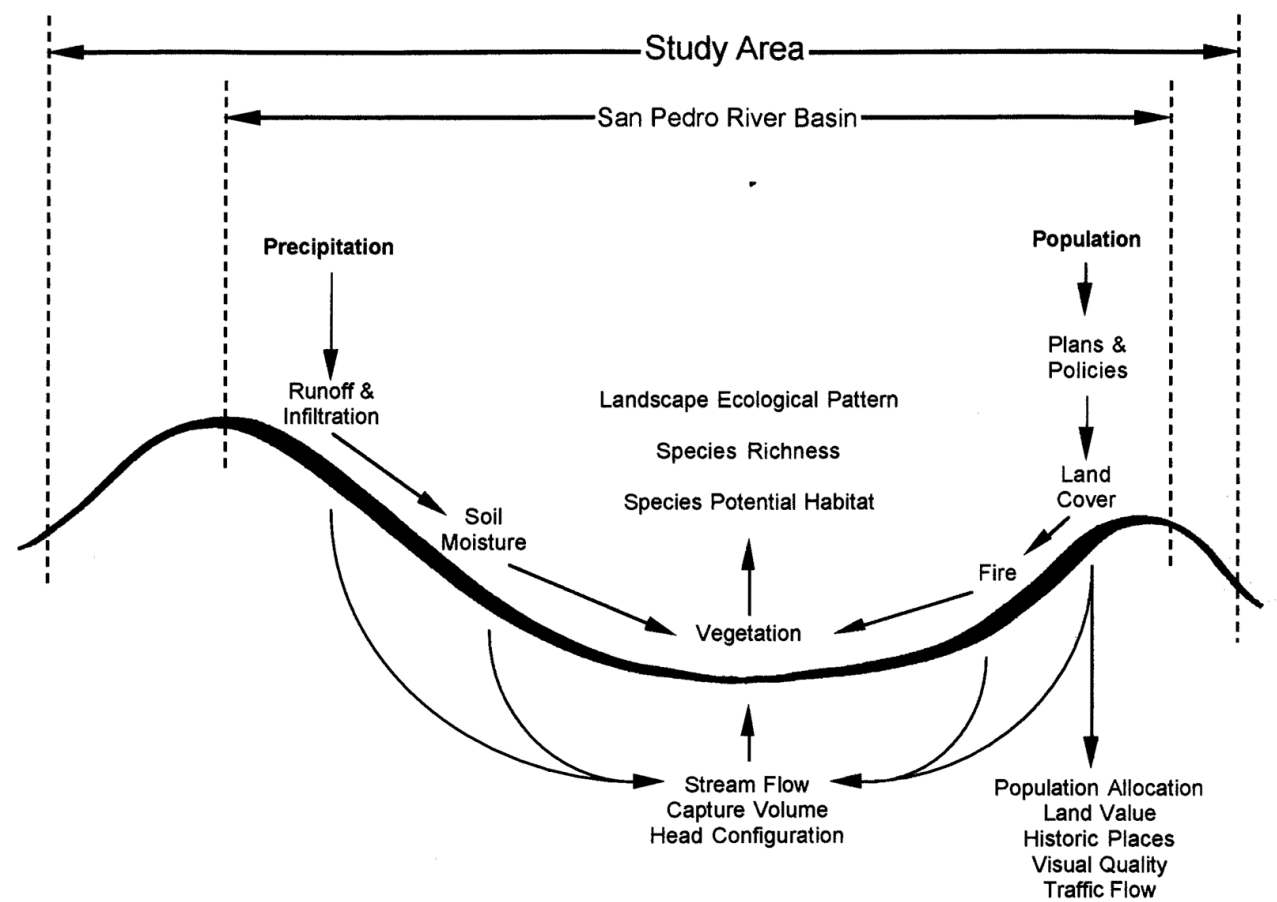

Figure 3. Sectional diagram of process model relationships.

(From: Poster presented at the 1998 SERDP Symposium, entitled Alternative Futures for the Upper San Pedro River Basin, Arizona and Sonora: The Region of Fort Huachuca, describing work funded by the DoD Legacy Program and conducted by the Harvard Design School, ERDC/CERL, U.S. Army TRADOC, the Desert Research Institute, the University of Arizona, and the Semi-Arid Land Surface/Atmosphere [SALSA] program.)

\section{Population Allocation}

Many military bases were sited in part because of relative isolation, away from urban and suburban areas. Now however, many of these same isolated areas are attracting residential growth. Understanding where and how development might occur along the fence line can help DoD land managers to anticipate possible impacts on shared resources (such as ground water supply) and downstream effects (such as exacerbated flooding).

\section{Historic and Cultural Resources}

Many DoD facilities contain historic buildings or have publicly accessible muse ums. The preservation of historically and culturally significant sites is generally accepted as a public good. Additionally, historic and cultural sites may also serve as development "attractors," drawing in services such as hotels and restaurants. The cumulative impacts associated with such development may affect ecosystems and other environmental factors within and around military installations, as well as the quality of life for personnel stationed in the region. 


\section{Visual Quality}

Knowledge of visual preferences within a region could assist a base in operating as a "good neighbor" by planning the perimeter of the facility so as to maintain (or create) some positive aesthetic quality.

\section{Traffic}

Highway improvements can serve as attractors for regional growth, which then adds to congestion in a cyclical sequence.

\section{Land Value}

This analysis will provide a basis for estimating the cost of fee-simple conservation strategies off-base.

\section{Change}

To assess impacts, it is first necessary to understand how the landscape might be changed. To simulate possible change, a number of alternative scenarios are created. A scenario can be defined as a specific spatial allocation of land uses at a specific time with clearly articulated assumptions. Since this spatial-temporal problem has an uncountable set of possible solutions, it is crucial to limit the number of alternatives, first to a comprehensive set of the "reasonable-toconsider" options and then to a set of "feasible options." I ncluded within this last set are those options that capture the central interests of the regional stakeholders. The actual future is not likely to be one of the extremes, but rather a politically feasible compromise.

Figure 4 illustrates the multiple consequences that could occur in the future based on choices made in the present. (Note that failing to make any active choice by simply allowing things to continue in their current trend also constitutes a "choice" or decision.) The letters in dark circles indicate modeled scenarios in a study. In a well-designed study, these different scenarios are designed to delimit a conceptual area enclosing "feasible futures" - the future scenarios most likely to occur based on present issues, concerns, and capabilities for instituting land use changes. To delimit "feasible futures," the most extreme of the identified "feasible futures" are modeled; for example, the greatest feasible urban development versus the greatest feasible degree of conservation measures. The deeply-shaded area bounded by the circled letters represents these "feasible futures." The lighter-shaded areas surrounding the "feasible futures" represent "reasonable futures" - futures which could real istically occur but which are less 
likely than the "feasible futures." Figure 4 illustrates conceptually that making the choice to implement one scenario - here Scenario D - leads in turn to a new set of possible outcome scenarios, while at the same time precluding other scenarios $(A, B, C, n)$ from occurring.

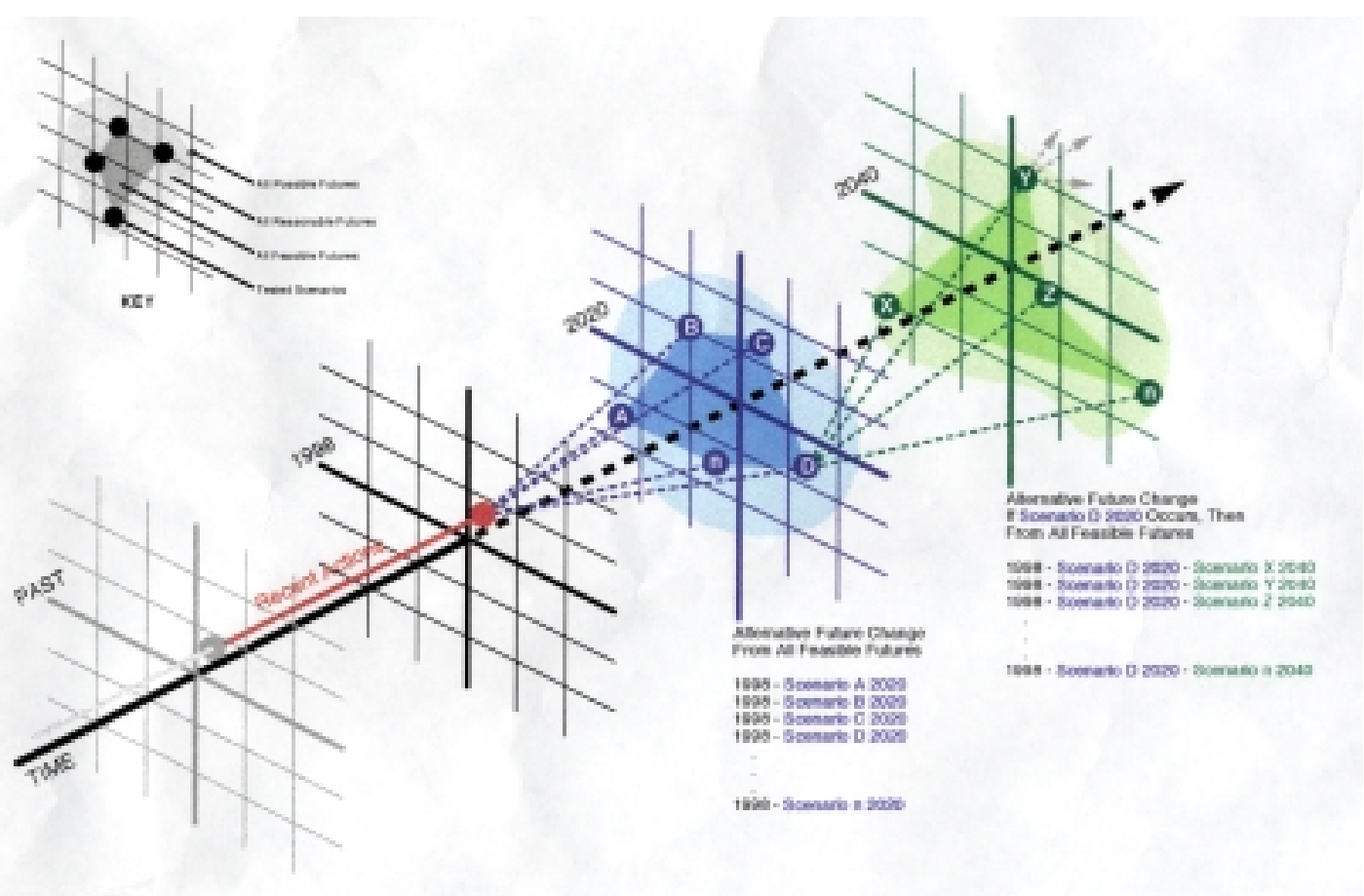

Figure 4. Future trajectories of present land use choices.

(From: Poster presented at the 1998 SERDP Symposium, entitled Alternative Futures for the Upper San Pedro River Basin, Arizona and Sonora: The Region of Fort Huachuca, describing work funded by the DoD Legacy Program and conducted by the Harvard Design School, ERDC/CERL, U.S. Army TRADOC, the Desert Research Institute, the University of Arizona, and the Semi-Arid Land Surface/Atmosphere [SALSA] program.)

\section{Impact}

To articulate possible strategies that can address regional land use concerns, a scenario-based planning study must not only assess the current situation in relation to the other stakeholders of the region, but must also consider what and how conditions might change in the future. These impacts have many possible metrics. Metrics of interest to military installations could include: noise levels, water runoff and groundwater recharge, water use, biodiversity, urban encroachment toward the installation, economic development, real estate value, and many others. Metrics that are relevant to each specific situation, and that can be modeled or estimated using existing capabilities, should be chosen for a scenario-based planning study of an installation and its region. 
These metrics can be individually tracked through time, as shown in Figure 5a. Thus, for example, the change in runoff hydrograph or in real estate value can be compared from year to year. The metrics can also be compared across scenarios, as shown in Figure 5b. Here, an example would be the surface water runoff produced in Scenario A compared to the runoff produced if Scenarios B, C, etc., were chosen. Process models are used to predict the various outcomes resulting from different scenarios. Examples of process models include hydrologic models, species population models, traffic models, economic growth models, and air quality models.

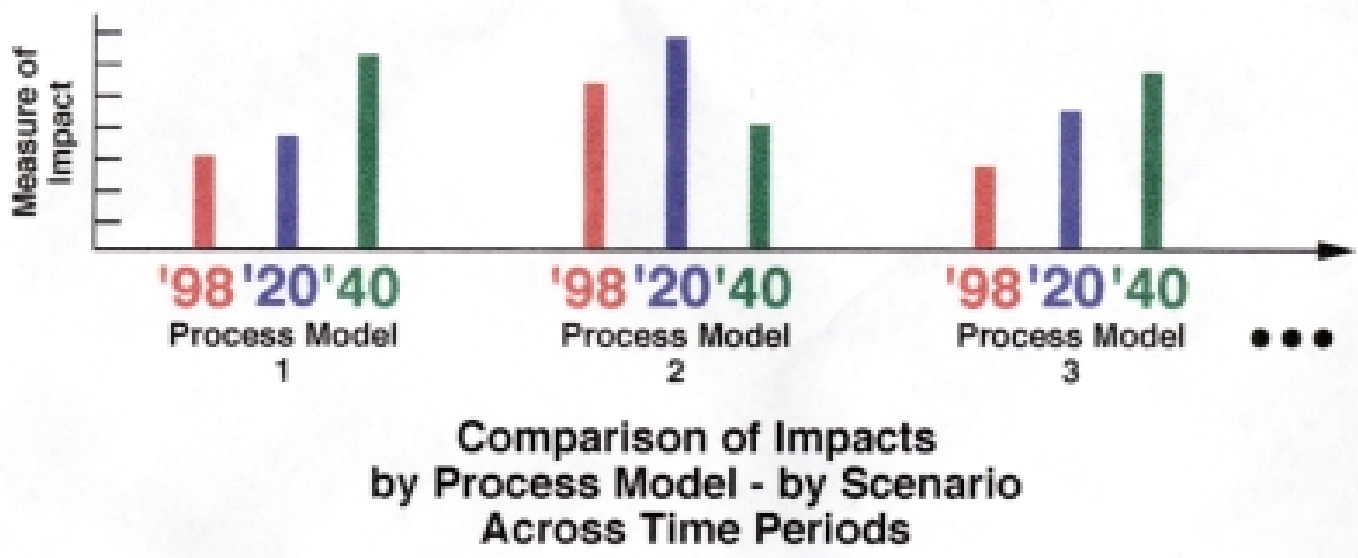

Figure 5a. Comparison of impacts through time.

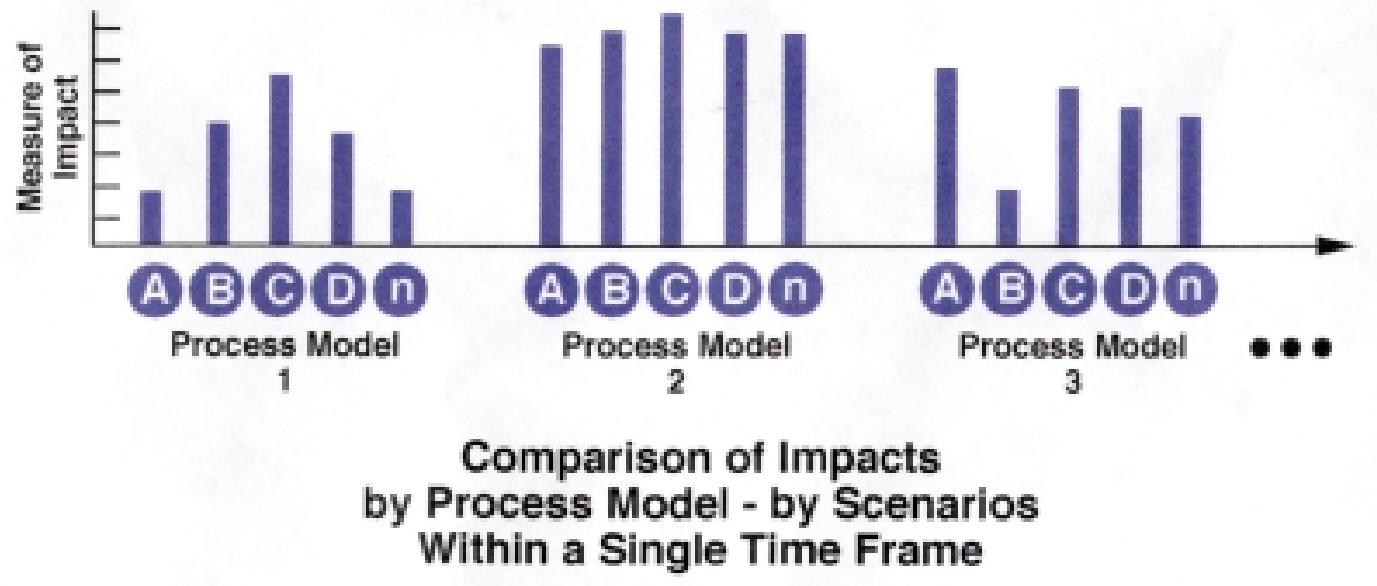

Figure 5b. Comparison of impacts by scenario.

(From: Poster presented at the 1998 SERDP Symposium, entitled Alternative Futures for the Upper San Pedro River Basin, Arizona and Sonora: The Region of Fort Huachuca, describing work funded by the DoD Legacy Program and conducted by the Harvard Design School, ERDC/CERL, U.S. Army TRADOC, the Desert Research Institute, the University of Arizona, and the Semi-Arid Land Surface/Atmosphere [SALSA] program.) 
If Process Model 1 in Figure $5 b$ represented acreage of valued species habitat, then Scenario $C$ would be best for this factor. If Process Model 2 in Figure $5 b$ involved traffic volume, none of the scenarios would be appreciably different from each other. If Process Model 3 represented level of wildfire hazard, Scenario $B$ would be the most desirable choice.

\section{Decisionmaking}

Making a scenario-based planning decision requires that the various criteria selected for the study be compared with one another. This means giving values to the impact metrics resulting from the analysis phase of the project. For example, the lowest rate of groundwater "mining" (removal in excess of recharge rates) would be ranked the "best" outcome, while the highest rate would be the "worst." A clearly understandable way to present this information for decisionmaking is to rank the results of the impact analysis from "worst" to "best," and arrange them in a matrix, as shown in Figure 6.

Figure 6 shows that Scenario B would be the best choice to make, based on the fact that it rates "best" in three of the four impact metrics.

Presenting information in this way makes an important assumption: that all parties agree on what is "best" and what is "worst." This is by no means al ways the case. Conflicting interests can cause people to assign conflicting values to certain outcomes. For example, to a person focused on conservation, large acre age devoted to conservation and a slow or dedining rate of development would seem best. To another person focused on economic growth, that scenario would not seem best, but rather worst. To a military installation, slow or negative encroachment of development toward the installation boundaries would seem best, while to a developer this would not be desirable. 


\begin{tabular}{|l|l|l|l|l|}
\hline \multicolumn{5}{|c|}{ Example Impact Metrics } \\
\hline & $\begin{array}{l}\text { Residential Growth } \\
\text { Near Installation } \\
\text { Boundaries }\end{array}$ & $\begin{array}{l}\text { Rate of } \\
\text { Groundwater } \\
\text { Mining }\end{array}$ & $\begin{array}{l}\text { Species } \\
\text { Habitat } \\
\text { Acreage }\end{array}$ & $\begin{array}{l}\text { Noise } \\
\text { Disturbance }\end{array}$ \\
\hline Scenario A & W & I & W & W \\
\hline Scenario B & B & B & I & I \\
\hline $\begin{array}{l}\text { Scenario C } \\
\text { B = Best outcome } \\
\text { I = Intermediate outcome } \\
\text { W = Worst outcome }\end{array}$ & W & B & \\
\hline
\end{tabular}

Figure 6. Example decision matrix for choosing a scenario.

(Adopted from Figure 133, p 128, Landscape Planning for Biodiversity: Alternative Futures for the Region of Camp Pendleton, CA, by Carl Steinitz et al., under work funded by the DoD/DOE/EPA Strategic Environmental Research and Development Program.)

People might agree, in principle, that groundwater mining is "bad." But if a low groundwater mining rate in a scenario is due to low or negative growth rate of the region, rather than to water conservation, then some parties would regard the "good" low groundwater mining rate as the result of a "bad" development growth rate, and hence would not rate it as "good" in their system of values. Everyone might agree, in principle, that they want to see valuable species habitat preserved, and hence would rate as "good" a scenario that did that. But if the scenario preserved habitat at what seems a high cost to them and low cost to their neighbors, then this outcome would not be rated as "good" as before. This type of situation can occur on military installations that take their environmental stewardship mandates seriously and thus become a refuge for endangered species, while uncontrolled development occurs around them and worsens the situation for them. These are examples of situations where an impact at first seems clearly good (or bad), but then changes value according to the context. Scenario-based planning is a helpful method for identifying and evaluating the full contexts of scenarios in order for participants to decide what their true values really are.

If conflicting values occur among participants in a scenario-based planning exercise, the logical approach is not to use "best" versus "worst," but rather "highest" 
versus "lowest" on each parameter where there is disagreement. High and low refer simply to the metric itself (e.g., high rate of residential development, low species habitat acreage), without assigning human preference values such as "best" and "worst." The resulting matrix to use in joint decisionmaking for choosing a scenario will not provide as simple and obvious a solution as is possible in the situation where all agree on values, as presented in Figure 6. Instead, discussion and compromises must be used in order to reach a decision. Participants can use existing software packages to rank their desired goods and bads, and compare them to assist in this kind of complex decisionmaking. However, without the information contributed by scenario-based planning, it is difficult for participants to understand the full context, implications, and the possible longterm outcomes of their choices. Consequently, it is difficult for them to evaluate and rank their preferred scenarios accurately. Scenario-based planning should provide the basis for final evaluation and choice of options, whether this is a simple or a complex process.

A number of factors influence the degree to which DoD personnel may become involved in scenario-based regional planning. Factors in favor of such collaboration between an installation and its regional neighbors include:

- preventing, moderating, or reducing regional land use changes that would interfere with the installation's execution of its mission;

- maintaining the installation's access to resources such as water supplies, transportation routes, and buffer zones around the installation;

- arranging for other entities besides the installation to maintain their "fair share" of stewardship responsibilities such as preservation of wildlife habitat, endangered species, and culturally valued sites and resources;

- ensuring recognition and understanding of the installation's interests, needs, and contributions as an inhabitant of the region, by non-military interests and political decisionmakers;

- minimizing the likelihood of land use incompatibilities, conflidts, and expensive "surprises" that occur due to lack of coordination among re gional land users;

- partnering with their neighbors to develop innovative "win-win" solutions to land use challenges in the region.

Factors that could potentially work against regional collaboration efforts by installations include governmental policies, practices, and attitudes that inhibit such collaboration, as well as the installation's staff resources and workload. Negative past history between an installation and its neighbors can also be an inhibiting factor. 
Being a key player in important regional land use decision processes will work very much in favor of the installation and DoD. Inhibiting factors should be creatively overcome to the extent possible, to allow the installation and its command to actively influence their own future by participating in regional planning and decisionmaking. Scenario-based regional planning is potentially a powerful tool for DoD to use in such efforts. 


\section{Users and Uses}

\section{Why and How to Adapt Regional Scenario-Based Planning for Military Use}

Why Adapt to Military Use?

The scenario-based planning approach has been applied to civilian sector urban and regional planning for more than 25 years. There has recently been a major scenario-based planning study at Camp Pendleton, CA. Camp Pendleton is one of the Marine Corps' most important installations, but more significantly, it is a military installation where development encroachment from outside its installation boundaries puts the installation mission at great risk. This same situation faces the military in many locations; in some, encroachment has already taken a severe toll on the mission capability of the installation. Without a knowledgeable planning approach in which the military can actively participate to help formulate its own future, these installations will be left subject to the decisions of local and regional development parties and other civilian decisionmakers. By participating with other regional stakeholders in formulating the future, the DoD has the opportunity to more directly ensure its own interests in preserving installation mission capability. Thus, scenario-based planning can provide one means of protecting and preserving the government's investment in its military infrastructure.

\section{What is Unique to the Military?}

Certainly no other land owner in the United States carries out the training, readiness, and test activities that are the responsibility of the military. Therefore, no other entity within the United States is going to invest in research on how to protect these training, readiness, and test activities. It is the unique responsibility of the military to stand with the planners of their communities and participate with them in presenting to the public these unique activities and the requirements that they imply. No one else will represent the military community's concerns besides the military, and managers must be knowledgeable and competent enough to do this effectively. 
Without an objective expression of military needs, the military land base within the United States is at risk. In the past, regions of some installations have become so encumbered due to regional development and other land use changes that their mission was severely restricted. The mission restriction then made these installations the target of Base Realignment and Closure (BRAC) studies. The result of this was:

- installation missions were threatened though no fault of the installation staff;

- if closure occurred, the government investment in that real estate and community was lost;

- $\quad$ if the mission was still valid, it would have to be realigned elsewhere;

- if realigned, the government had to reinvest in the real estate of the new community to support an additional mission;

- that added mission would encourage additional local devel opment, and

- the additional local development might threaten the new installation mission.

The point is that if the military does not begin to control its own destiny, the issue of development and encroachment is self-replicating. That is why realignment of a mission can be a perpetually self-defeating action on the part of the military. As has been shown many times in the past, no one but the military will represent its unique requirements to the communities in which the installations reside.

\section{Cost}

Cost is always a concern. The current standard is for planners and particularly budget analysts to look at the cost savings obtained from a single change without looking at the true costs of the action in a long-term context. The colloquial expression, "Penny wise, dollar foolish" applies. Further, no one in the military disagrees that planning for future military actions is valuable and provides a positive cost benefit to the military. Regional planning and scenario-based planning may be a new concept in the military, but the same logic applies.

That said, we can turn to the question of costs of failing to adopt a regional scenario based planning approach. As mentioned in the previous section, not participating in planning may put installation missions at risk. At the least, planning will delay the day when installation missions fall in the "at-risk" category. Even this saves government funds in that future-value money costs less than present-value money. 
On a broader scale, that of the nation in general, it is apparent that the United States has considerably less open available space than it did a generation ago. All installations have to face the pressures of their communities to a greater or lesser extent. Further, attitudes have also changed in a way that makes what was once called "waste land" into valuable natural resources. A good example of this was the Mojave Desert where the Army, Navy, and Marines sited large installations in order to be out of the way of civilian communities and interests. Now these lands are publicly considered to be treasured resources, which means DoD care must be of a significantly higher caliber than was originally or even recently anticipated. The point is that large areas of unencumbered land available for military actions within the United States are simply not going to be available to the military in the future as they were in the past. Therefore, there is no alternative for the military but to participate in determining regional land use planning activities. In the sense it is unavoidable, it is cost effective.

Further, not participating and objectively representing the military needs to the other regional stakeholders invites controversy and legal entanglements. To the extent that these can be mitigated and avoided, the military can save a great deal of staff time and planning delays.

All this having been stated, experience shows that the actual cost of conducting ad hoc scenario-based planning studies for an individual location can be relatively high, sometimes in excess of $\$ 1$ million. This is partly because each study is developed individually, from scratch, and does not make full and efficient use of existing tools and resources al ready developed or under advanced development within the military, other government agencies, academia, and the civilian sector. Significant savings in the cost and time involved in a scenario-based planning study for a region and an included military installation can be anticipated under the following circumstances:

- A more generalized, standardized approach or protocol is first applied, and only if this does not provide sufficiently detailed information to solve the problem does the installation turn to the more expensive, individuallydesigned study process.

- Full use is made of existing or developing software, models, integrated systems, web-based databases, and other resources that can streamline the analysis process. To do this also requires a protocol to guide the procedure.

In addition to savings that can result from applying a standardized protocol, other cost reductions can be expected due to changes such as:

- decreased costs of computer equipment,

- decreased costs of supporting data access,

- increased availability of Federal, State, or academically generated models, 
- increased ease of access, communication, and presentation over the internet,

- increased familiarity of academic institutions with the concept (i.e., there are more groups qualified to carry out a study).

However, with increased capability, the ability to integrate new concepts increases so that a better study can be carried out. This implies an increase in the accuracy and usefulness of the studies, without any great increase in the cost involved, as long as there is a protocol to guide the efficient use of these re sources.

\section{Level of Detail}

As detail increases, predictive quality and power of planning increases, but cost goes up geometrically. Remote sensing images have provided an adequate base for several years. At the time of this document, the standard cell within a GIS grid has a size of 20 to 30 meters on an edge. This has not materially changed in the past couple decades. Newer satellite imagery may provide higher detail, but recent announcements indicate that the cost will be geometrically increased, slowing its adaptation for use at the regional scale.

In practice however, if the lowest common denominator is "land use type," then one really need not adopt a resolution below the smallest land use type with which one reasonably wishes to deal. At the current time, this would be either a high-density single-family residence, or the width of a transportation corridor. Either is roughly one-sixth acre in size. The reason for using higher resolutions is that there is no guarantee that the base map or the imagery one starts with will identify the land use accurately. Therefore, using a more detailed resolution allows for some degree of inaccuracy, or land-use overlapping. Source data and cost are often limiting factors. As computer power goes up and disk storage costs go down, these are no longer significant concerns in determining the degree of detail needed.

\section{Need for a Standardized Approach}

\section{For Installations}

The use of compatible data sets among the regional participants and stakeholders allows much easier cooperation and coordination. A scenario-based planning study establishes this baseline and promotes cooperation, coordination, and integration among the installation and its neighbors in the planning. 


\section{For MACOMs}

MACOMs have a need to provide cross-comparisons among the installations for which they are responsible, to ensure that resources are judiciously allocated according to greatest need and greatest likely return on investment. Scenariobased regional planning can provide the MACOMs with necessary data to help ensure the best allocation of perennially scarce resources. An understanding at the MACOM level of feasible scenarios in the regions of their installations and of which scenarios would most benefit DoD, would allow the MACOMs not only to allocate financial resources but also to help allocate staff technical expertise where it is most needed, and indicate where the MACOM might use its political influence to improve an installation's situation. This procedure can help prioritize the direction of resource development and flow, for all types of resources including fiscal, staff, and political.

\section{Anticipated Users}

DoD

An installation can use scenario-based planning to project the potential effects of anticipated regional land use changes and trends, enabling the installation to be proactive in bringing about desired changes, altering or mitigating undesired ones, and preparing for the most likely changes. The information provided by scenario-based planning can help get an installation out of a relatively powerless, reactive position and support its ability to be an effective player in the larger context of the region's future. The installation will be able to project the likely impacts of problems such as encroachment, generate possible alternative responses, and come to the "regional table" with information to support its best interests. In pursuing this scenario projection, a number of installation offices and personnel will need to collaborate in the study and in applying the results. This type of collaboration has been noted al ready as being one of the most beneficial effects at locations where the approach has been applied.

Installations can also use a scenario-based planning protocol as a means of promoting and participating in collaborative regional planning and problem-solving with Federal, State, and Local agencies, and other stakeholders. Rather than being reactive or relatively helpless in the face of the regional political process, the installation will be able to take a proactive and leadership role in collaboratively addressing regional concerns. 
Installations and MACOMS use a scenario-based planning protocol to help create Environmental I mpact Statements (EISs) that can defensibly evaluate cumulative and integrated effects of their actions. Using current procedures, Army EISs have been challenged in court as inadequately addressing cumulative impacts.

MACOMS can use the scenario-based approach to project likely challenges that will appear for their installations in the future. Knowledge of approaching challenges will allow MACOMs to plan and budget ways and means to address the challenges proactively. Rather than being buffeted around by regional trends and subjected to pressures such as lawsuits, installations with the support of their MACOMs could be leaders for their regions in anticipating the future and acting constructively on that knowledge.

MACOMs can also use the protocol to conduct scenario-based analyses of problems that may face a number of installations concurrently. Examples are the challenges related to management of the Red-Cockaded Woodpecker, and challenges related to encroachment around installations. Possible future scenarios can be projected in a general way for the whole set of affected installations. The results can be used to support budget projections and other MACOM planning, to devel op political strategies, and as a scoping or screening procedure before de-

ciding whether to do more in-depth, site-by-site analyses. Such studies can also support programmatic EISs.

At the Service level, the protocol can be applied to help inform BRAC decisions, mission relocations, land acquisitions, decisions about how to decommission facilities, and other actions that influence and are influenced by regional factors, trends, and political processes.

\section{Non-DoD}

The advantages of a standardized protocol for scenario-based planning are not limited to those in the DoD who fund the work. Promoting coordination among regional stakeholders is one of the primary objectives of any scenario-based planning initiative. Their active participation will result in a better integration of DoD and community concerns and directions for future plans and area developments.

Often other Federal lands are adjacent to or integral to the military training/test locations. Common Federal neighbors of installations include the Forest Service, Bureau of Land Management (BLM), Bureau of Indian Affairs, and National Park Service. Many of these organizations have relatively technologically ad- 
vanced planning and management expertise within their staff resources. They also are usually interested in long-term management objectives as part of their regular mission. Therefore, managers in these organizations can be expected to be receptive to the objectives and methods of scenario-based planning.

In the past, one might have expected that at the more local levels of government the level of technological sophistication would decrease in comparison with Federal agencies. In today's rapidly advancing society, this may not necessarily be the case. Depending on the availability of funding and local expertise, local planning groups may understand and participate at a sophisticated level of input.

Two levels of local agencies have similar objectives of regional planning: State and County planning departments. The State may view the scenario-based planning protocol as an opportunity to more carefully integrate a region of the State into the predicted fabric of the rest of the State area responsibilities. At this time, the State planners are likely to be interested in using a protocol study as a demonstration of what can be accomplished in other localities of the State in terms of future trends and options for regional growth. Along these lines, it might be well to remember that installations and the regions they affect may go beyond a State line. In this case, encouraging the active participation of nearby states will be useful.

Most often the County planners are those with the greatest immediate interest in a scenario-based planning study since the area of coverage will be close to the size of one or several counties. County planners are likely to see scenario-based planning as a means of demonstrating to the individuals and stakeholders within their area of responsibility the results of good versus poor planning decisions. In a sense, it is a planner's educational tool. Though individuals in the planning arena may have a sense of what the real effects of their decisions may be, many other groups do not have this background, or may be unwilling to accept the reasonable results of planning decisions. Thus, for County planners, a protocol for affordable scenario-based planning is likely to be considered a very important resource for helping the local communities make intelligent planning decisions, or get needed planning documents accepted by the County planning boards. This widespread involvement is particularly true as an aid for decreasing controversy or potential legal action against the board. Therefore, installations that seek regional partnership in executing a scenario-based planning study are likely to meet with high interest and active participation of County planners. The actual running of a set of alternative scenarios after the completion of the initial protocol study may fall largely to County planners and staff elements. This involvement of County planners would be a very desirable result 
of implementing such a study, as it would foster good community relations and working partnerships between the installation and its neighbors.

Often City and Town governments are interested in fostering development to increase the local tax base. Occasionally these individuals do not have a planning background and therefore may find it difficult to visualize the implications of their actions. The alternatives that result from several runs of the scenariobased planning protocol would clarify the results of local planning decisions. As with other levels of local government, it is useful to publicly present the alternative scenarios resulting from the study so that the constituents more dearly understand what their appointed or elected officials are proposing and why. An objective presentation of analytical results can help bypass fruitless political debates based on unverified assumptions about the future results of present decisions. Similarly, objective presentation of reasonable alternatives via a scenario-based planning protocol method could decrease the likelihood of nuisance legal suits later being brought against the local government due to lack of clear public understanding during the decision process.

Various interest groups and stakeholders are likely to find scenario-based planning useful. Interest groups generally have a point of view to which they are committed. One of the advantages of presenting the results of alternative scenarios is that those individuals and groups who formerly thought of each other as being at the opposite end of the spectrum often find that they are not so different, or that there are areas where both can benefit by cooperation. Occasionally the alternatives show that groups opposed to each other have good reason to be opposed. In this case, the presentation of the scenarios provides a means of keeping the discussion open and honest, and less encumbered with questions that tend to deflect the discussion away from reaching a well informed decision.

As individuals, we are all affected by the planning actions that occur at every stage of the decisionmaking process. Public presentation and discussion of the results of alternative scenarios is likely to result in a clearer definition of what each individual and group has to gain and lose. Based on that definition, individuals are empowered to take actions they feel appropriate. Making decisions openly based on the best available data and judgment is the ideal goal of democratic self-government. 


\section{Potential Applications}

\section{Installation Management}

Installations could use a scenario-based planning protocol both to allow them to become more effective players among all stakeholders in a regional planning context and to aid routine base operations (BASOPS) activities.

In a regional context, scenario-based approaches can be used to project the potential effects of anticipated regional land use changes and trends, enabling an installation to be proactive in bringing about desired changes, altering or mitigating undesired ones, and preparing for the most likely changes. The information provided by scenario-based planning can help get an installation out of a relatively powerless, reactive position and support its ability to be an effective player in the larger context of the region's future. The installation will be able to project the likely impacts of problems such as encroachment, generate possible alternative responses, and come to the "regional table" with information to support its best interests. In pursuing this, a number of installation offices and personnel will need to collaborate in the study and in applying the results, which has been noted already as being one of the most beneficial effects at locations where the approach has been applied.

Installations could also use the protocol as a means of promoting and participating in collaborative regional planning and problem-solving with Federal, State, and Local agencies, and other stakeholders. Rather than being reactive or relatively helpless in the face of the regional political process, the installation will be able to take a proactive and leadership role in collaboratively addressing regional concerns.

In addition to allowing an installation to become a more effective player amongst all stakeholders in a regional planning context, scenario-based planning outputs may be used effectively to guide BASOPS decision processes. Scenario-based assessments could affect the entire breadth of both routine daily BASOPS activities and/or long-term strategies for facilities and infrastructure. For example, master planners could use demographic projections to identify opportunities to partner with Local organizations to provide facilities and services off-post rather than to include them in long range installation master plans. In true partnership with off-post stakeholders, facilities and functions could be accommodated on-post and shared with off-post organizations where off-post demands are insufficient to be economically viable for the short term. An example might be that off-post needs for child care in the short term are insufficient to support facilities, making partnership with on-post providers more viable, where long term 
projections and changes in on-post demographics will make off-post service provision more cost effective.

\section{Mobilization Planning}

Predicting the impact of mobilization missions on installation infrastructure is a fundamental purpose for installation mobilization planning. Successful identification and planning for required expansion assets allows for a smooth transition from peacetime to mobilization missions. By extension, impact can also be determined on the surrounding communities and regions.

Mobilization planning is little more than traditional installation master planning with an increased stationing (population demographic) and revised space and planning criteria (reduced allowances). In the past, there were two different types of plans that might be prepared: expansion capability plans when mobilization missions were not fixed, and mobilization master plans when mobilization missions were well defined. Both plans are based on the accurate identification of facilities and infrastructure that are required to meet expanded mission requirements. The mobilization plan is to a known stationing level, while the expansion capability plan is to a theoretical limit or carrying capacity of requirements to meet a series of increasing stationing levels. Today mobilization missions are predominantly known and plans developed through modification of facilities al gorithms in Reap Property Planning and Analysis System (RPLANS).

Scenario-based planning can be an essential tool in mobilization planning. Mobilization planning cannot occur successfully without adequate consideration given to local, regional, and even national factors affecting installation mobilization missions. The plan must take into consideration, for example, the transportation systems, water, power, adjacent land-use (encroachment), etc., and predict the future impact on the installation's capability to carry out mobilization missions. Scenario-based planning techniques can be successfully used to predictively model the future land-use patterns in and around military installations, and the impact of the patterns on mobilization requirements.

\section{MACOM Summaries}

Devel opment of predictive scenarios adds another dimension to information supporting MACOM decisions. Installation requirements and the local/regional influences on them need to be successfully compared across installations in order for MACOMs to allocate resources effectively among the installations they are responsible for. With appropriate future scenarios for all installations within a 
MACOM, local environments can be comparatively evaluated and mission re quirements successfully "level ed" across the command.

For strategic and economic purposes, for example, MACOMs are often faced with decisions such as where might be the best location for a new mission or for the relocation of a mission from a closing base. Sometimes the decision lies within the purview of the MACOM, in other cases (such as BRAC) it lies above the MACOM level. While MACOMs are not responsible for BRAC decisions, they do provide input at various stages in the process, and must implement the final results of BRAC decisions.

Thus, MACOMs must deal, at times, with questions such as: Which areas might be more receptive to new missions? What are limitations to acceptance of the new mission? Will there be adequate land, power, and water in the future? What might the impacts of fielding the new mission be in a particular location? Comparison of the myriad of factors "outside the fence" affecting the decision could be more successfully accomplished with a scenario-based approach to aid the MACOM decision process.

MACOMs may use metrics to compare situations and needed resources among their installations. Some metrics might measure the urgency of issues such as the presence of Threatened/Endangered Species, Native American and other cultural resources issues and requirements, noise problems, water issues, lawsuits and consultations that may be looming on the horizon, and others. An advantage of scenario-based planning is the use of common metrics for different scenarios so that all the scenario outcomes can validly be compared with one another. A MACOM could apply a scoping-level protocol for scenario-based planning to all of its installation regions. The resulting scenarios could help the MACOM compare needs and issues of concern among the installations, allowing the MACOM to allocate its resources (funding, expertise, staff time, etc.) most efficiently and effectively. Scenario-based planning can also be a very valuable tool for an installation or its MACOM to participate effectively in consultations and permitting procedures, such as those involved in endangered species management, cultural resources preservation, and clean water/air management.

\section{Threatened and Endangered Species (TES)}

One could demonstrate Ecological Risk Assessment Protocols for a real installation problem or need within a scenario-based planning protocol framework. For example, a cumulative risk assessment to TES or a cumulative risk assessment to training could each be examined in this context. Once risk assessment protocols are applied to identify the probable risks, an individual can use a model 
(e.g., the Ecological Dynamics Simulation (EDYS) Model) as the analytical tool to complete a screening-level risk assessment to identify the real risks and then proceed with a dynamic risk assessment to quantify how a real risk fluctuates over spatial and temporal scales.

For example, is vehicle traffic through or near TES nesting sites only a problem during the nesting season or are contaminants from smokes only a problem during the time of year when the species is feeding on certain insects that tend to accumulate the contaminant? Are TES a risk to stopping training only when habitat outsi de the fence reaches some critical level? Once dynamic risk assessment had been demonstrated as a useful combination of tools, one would then implement this combination of tools for use with the scenario-based planning protocol tool.

\section{Natural and Cultural Resources Management}

Management of natural and cultural resources involves a great deal of planning, using standard procedures such as the Installation Natural Resource Management Plan (INRMP) and Installation Cultural Resource Management Plan (ICRMP). These resources do not exist in isolation; they influence and are influenced by events in the surrounding region. Installation managers cannot effectively plan many of their natural and cultural resource management needs and actions into the future without reference to the future of the surrounding region. Issues of water supply, ecosystem fragmentation, development, encroachment, public or tribal demands for cultural and recreational amenities, changes in public policies and the management of surrounding public and private lands, and many other factors can influence the status of natural and cultural resource management on the installation.

Scenario-based planning can be an extremely useful tool for installation managers to comprehend and plan for regional changes that will affect their management responsibilities. Collaborative scenario-based planning also provides a way for installation managers to influence decisions and policies in the region, allowing the inclusion of the installation's interests along with other interests in the region. One important issue where this kind of application would be very useful to DoD is in regional discussions of the "fair share" of installations versus other agencies and entities in providing wildlife refuges, biodiversity resources, and other environmental protection needs. DoD often is left with the perception that it is expected to provide more than its "fair share" of such public goods. 


\section{Tribal Use Negotiation}

The foundation of all negotiations with Native Americans is respect. F requently, and for good reason, tribal representatives are reluctant to be specific in negotiations. Negotiations must begin with the realization that Native Americans have a different worldview. As Tessie Naranjo (Santa Clara) has stated, "Traditional Native Americans believe that everyone and everything exist in an integrated and pervasive system of relationships." Careful listening must replace lip service. During a lengthy series of discussions between representatives of the Caddo Nation and Fort Polk, LA, mutual trust evolved into sensitive discussion of a reburial area that could be visited by members of the Caddo Tribe. Site elements most important to the Nation were related to traditional beliefs such as nearness to water, natural sounds, wild plants and trees, and no maintenance because return of the deceased to the natural world maintains their relationship. Negotiations that respect and honor a different worldview can capitalize on the best in land use planning. A scenario-based planning protocol would ensure full participation by tribal officials and members in the regional planning process, and promote their influence over their own future in the regional context.

\section{Community Relationships}

The purpose in making the outcomes of different policy alternatives obvious and objective is so that everyone can understand clearly their implications. Normally, individuals feel better if they believe they are working with others who forthrightly and honestly express their concerns and direction. Even if they do not agree with the direction, respect - and hopefully trust - can mature under these conditions. The protocol can be a means of providing the climate where this can occur. It can motivate the entire community toward a vision of the future that benefits everyone as well as explicitly expressing shortcomings and drawbacks within a plan of action. If the community decides that the drawbacks are too great, they still have the option of working together to make a change for the betterment. Installations with access to the scenario-based planning protocol would have the opportunity of taking a leadership role in promoting these beneficial interactions with their local communities.

\section{Regional Applications}

It is within the complexities of the regional context that the protocol has its greatest application potential. Usually, as the areal extent increases, the number of stakeholders involved also increases. As this number increases, the confusion as to which future alternative is most likely to occur also increases. A scenario-based planning protocol can provide an objective presentation and 
evaluation of future changes that are likely as a result of policy decisions, and can provide a basis for objective discussion of decisions and directions. Regional planning support technology has moved forward to the point where complicated issues at a regional scale are entirely practicable areas for concern. Balancing of competing dynamics stemming from the concerns of different parties is made more objective and public. Competing concerns may include military land uses, forestry, residential development, conservation, transportation development, water resources management, public safety, or soil conservation, to mention a few. 


\section{Technology Context}

\section{Information Management}

A central GIS can be the repository for data, models, and scenarios.

\section{Scenarios and Stakeholders}

Alternative land use scenarios in the form of land allocation maps, policy guidelines, and assumptions about population growth and long-term climate change, form the basic input to the GIS system. Model results from differing scenarios can be compared to generate estimates of future vulnerability of the installation in critical concerns, as defined by the selected models.

\section{Internet}

The central servers for the GIS system can be connected to users through a highspeed fiberoptic link to the Internet, so a remote location can readily access material, providing input in the forms of data, models, scenarios, or commentary.

\section{Resources From the Internet}

The wealth of information available from the Internet will lend support to scenario-based planning processes. Sources range from information on basic philosophy of futures and forecasting, through planners, consultants, and institutions developing or practicing scenario-based approaches, to detailed methodologies for scenario development on a wide range of topics/purposes. Scenario-based planning is as important in the corporate world to develop strategic plans to guide corporate futures as it is for planners to shape the future of regional environments. Appendix A displays the results of a brief search for resources on or related to scenario-based regional, urban, and/or master planning and typifies the information available. Information on scenario development for corporate or business strategic planning was dominant. Appendix A displays the search results grouped as follows:

- Strategic, Futures, and Scenario-Based Planning Papers and Resources

- Futurists (General)

- Military Strategic and Scenario-Based Planning 
- Sources, Pointers, and Bibliographies

- Infrastructure Analyses, Studies, and Models

- Governmental Planning Groups/Associations.

Appendix B provides a list of Urban, Regional, and Environmental Planning programs and departments at educational and research institutions, as a potential resource of expertise. Civilian sector consultants are also widely available; both sets of experts could make use of a scope of work based on a militaryadapted protocol for scenario-based planning.

\section{Hardware and Software}

The central computing system can be networked to an array of workstations and file servers with massive amounts of central disk space allocated for this study. Printers, plotters, slide-writers, and other output devices can enable the production of reports in various formats.

\section{Data Management System}

Digital data can be collected from a variety of public sources including the United States Geological Survey, Environmental Protection Agency, United States Army, U.S. Forest Service, Fish and Wildlife Service, State, Local, and Tribal agencies, and many others. All original data-maps, charts, tables, etc., should be annotated with a metadata (data about data) file. This file should include the data source and other salient characteristics such as date, units, and resolution. As data are translated and combined into standard formats, common spatial units, spatial projections, lexicon, etc., new metadata files are created. Data documentation throughout the project is an important component for an eventual technical transfer.

\section{Models and Interoperability}

Computer-based model structures, systems, and modeling capabilities should ideally be assembled, adapted, or created to support the scenario-based planning protocol. Critical processes to be modeled include economic and demographic models, visual quality, traffic flow, land value, fire management, storm water runoff, soil moisture, groundwater head configuration, groundwater capture volume, stream base flow, vegetation dynamics, landscape ecological pattern, species richness, and a suite of single species potential habitat models.

The models may be run either on the central computer system or at satellite locations asynchronously. In several instances, the output of one model is used as 
the input of another model. Ensuring that the outputs of each chained model are acceptable as inputs to other models is one of the greatest challenges to an integrated system. The development of the Land Management System (LMS) headed by the Corps of Engineers is expected to provide this kind of interoperable modeling environment and capability, which will be of inestimable value in designing and then supporting a scenario-based protocol for military use.

\section{Information Technology Access}

\section{Web Access and Uses}

With the advent of the Internet, information exchange has become much faster and much easier. This speed and accessibility will also apply to a digitally based protocol procedure. There is currently no technological reason why the user commands needed to run a protocol session cannot be submitted using a Web interface. The parameters of a specific run could then be transferred to the location where the hardware and software actually reside, submitted to the system, run, and the results provided back over the Internet to the user within a matter of moments. In fact, some of the more recent studies (e.g., Upper San Pedro/F ort Huachuca) have depended on Internet interaction for at least a portion of their input. It is recommended that a web-based protocol procedure be developed to take advantage of such powerful and flexible capabilities.

One of the advantages of using a digital format is that the results can be presented in a manner that makes them most useful to the audience. Normally the analysis is run within a GIS that generates spatially explicit results. These results are then collated into tables and further collated into descriptive summaries. Thus, the presentation of the results can be any graphical form using maps, 3-D presentations, time-series animations, tabular information, and written text. Each format may also automatically be linked to photographs, Internet pages, and even the offices of concerned stakeholders. By these means the resulting materials can be refined to match the purposes of the presentation and for the type of audience.

\section{Existing Technologies}

A number of existing and under-development technologies are likely to provide excellent input for a scenario-based planning protocol, and many may likewise be able to use protocol outputs as inputs for their analyses. Some of the most im- 
portant candidates for such interaction with a scenario-based planning protocol are described in the following sections.

\section{Infrastructure}

From the viewpoint of installation master-planning, the most important automated tool for the identification of facilities and infrastructure needs is RPLANS. This system uses population information in the form of units stationed (Army Stationing Installation Plan [ASIP]), existing and planned, and real property information (Integrated Facility System [IFS]) as the basis for the identification of all facilities and infrastructure requirements. Protocol applications will need to interface with RPLANS and vice versa for effective installation application of scenario-based planning. RPLANS has already been successfully integrated with IWRAPS (Installation Water Resources Analysis and Planning System) to model future water demands in the installation environment.

\section{Real Property Planning and Analysis System (RPLANS)}

The RPLANS is an integrated, automated planning tool that provides the capability to readily and efficiently calculate peacetime facility space allowances for an entire installation or individual units in comparison to available real property assets for a wide range of facility types.

\section{Army Stationing Installation Plan (ASIP)}

ASIP is the Army's official data source that relates current and planned training populations of all tenant and reserve organizational units to an installation to provide a basis for its real property planning and management support. Individual force structure elements are tracked by Unit Identification Code (UIC). The ASIP is updated semi-annually and assists installations to better manage and supervise manpower and equipment authorizations fed from other Department of the Army databases. These data bases include the Department of the Army Authorization System (i.e., TAADS), Army Training Resources Requirements System (ATRRS), and Structure and Manpower Allocation System (SAMAS). Key data elements of the ASIP include the current and projected

Modified Table of Organization and Equipment (MTOE) and Table of Distribution and Allowances (TDA) of all activities and their associated training loads assigned to train at that installation. 


\section{Integrated Facility System (IFS)}

The IFS is a facility engineer automated information evaluation system that encompassed life cycle management of real property resources, and is the official source of real property information for the Assistant Chief of Staff for Installation Management. In addition to real property information, the system performs a wide variety of other functions such as work estimating and work-order tracking. There are two levels of the system: the installation level and the headquarters level (now called Executive Information System).

\section{Engineered Management Systems (EMS)}

The EMSs provide the automated procedures and tools required to implement proactive management of installation maintenance and repair activities. The EMS proactive management approach manages facilities and infrastructure by determining maintenance to be planned, when it should be programmed, and the consequences if the work is not completed, using long-term, life-cycle perspectives and sound engineering-based measures and procedures. An EMS is a technology-based system that provides a functional manager with automated procedures and tools to support the planning, programming, and budgeting of infrastructure facilities maintenance and repair.

There are three main categories for EMSs: Transportation, Vertical Structures, and Utilities. Transportation EMS includes Micro PAVER, RAILER, and WALKER. Micro PAVER relates to pavements and unsurfaced roads. RAILER relates to railroad trackage, and WALKER relates to sidewalks. Vertical Structures EMS include ROOFER and BUILDER. ROOFER manages roofing systems, and BUILDER manages elements of buildings and vertical structures. Utilities EMS include HEATER and SEWER. HEATER manages heating systems, and SEWER governs sewer pipes and systems. Several other Utilities EMS are under development and encompass a wide range of utility systems including electrical, cooling, sewer, and piping systems.

\section{Utilities Models}

Accurate modeling of regional utility infrastructure networks is another critical component of scenario development. The capacities and locations of existing networks, the availability of the commodity being distributed/collected and limitations imposed by the need for extending or increasing utility capacities are equally significant in forecasting future land use possibilities. 
As with transportation modeling, Army master planners do not typically make use of regional or large-scale modeling of utilities networks in the development of installation master plans. Utility studies are conducted primarily in conjunction with major new construction programs to determine the need, extent, and requirements to support new facilities. Similarly, studies are conducted of existing systems to determine the necessity and scope of repair and maintenance work. A substantial need exists, however, to forecast and plan for all future utilities needs including gas, electric, water, storm sewer, sanitary sewer, and communications, in a regional context.

\section{Land Management System (LMS)}

The Corps of Engineers is developing an umbrella system called LMS. The purpose of LMS is to provide a single interface to access the many management systems the Corps of Engineers and the Army have developed and to which the installation professionals require access. Basically, a user input for a specific program can be submitted to that program via a standard user interface protocol. This will provide a powerful, integrative, and user-friendly environment for the complex modeling requirements of scenario-based regional planning. A scenario-based planning protocol will also be a valuable addition to the LMS suite of protocols. An LMS environment will also release the user from the requirement of installing and managing many different software packages. The LMS is a web-based interface. More information about LMS can be found the following website: http://www.denix.osd.mil/LMS

\section{Army Training and Testing Area Carrying Capacity (ATTACC)}

The Army Training and Testing Area Carrying Capacity (ATTACC) is a methodology and an integrated decision support system used for estimating the operations and support (O\&S) costs of using Army installation lands for training and testing purposes. The ATTACC methodology includes specific processes and algorithms to predict land rehabilitation and maintenance (LRAM) requirements based on training and testing loads and environmental conditions. The two major objectives of ATTACC are to:

- I Ientify training and testing land carrying capacity; and

- Establish a model to predict LRAM requirements based on training and testing usage.

ATTACC is the standard I ntegrated Training Area Management (ITAM) methodology for estimating training land carrying capacity by relating training load, land condition, and land maintenance practices. When the costs of these land 
maintenance practices are considered, ATTACC also provides a means for estimating future LRAM costs based on future training requirements.

The ATTACC analysis has been automated as a stand-alone tool for Headquarters, Department of theArmy applications. To make ATTACC useful for installation land management, elements of ATTACC have also been integrated into the automation tools most commonly available to ITAM and range control users. These tools consist of the Range Facility Management Support System (RFMSS) and the Arc View GIS, for which ITAM has developed a customized application called "MAGIC." Because RFMSS and GIS/MAGIC are widely used to schedule and manage training land and facilities, the integration of ATTACC with these tools allows ITAM managers to apply the principles of ATTACC to directly support land management and scheduling decisions. ATTACC and the other systems listed here that interact with it are all likely candidates for useful input sources for a scenario-based planning protocol, and may also make good use of protocol outputs as inputs for their analyses.

More information about ATTACC can be found in Appendix C and at: http://www.army-itam.com/publications/pamphlet350-4/appendixl.htm

\section{Ecological Dynamic Simulation System (EDYS)}

A PC-based model, EDYS, has been devel oped for modeling the process of secondary plant succession and the impact of training/testing land use and land management activities on plant succession.

The primary mission of the Army is to train soldiers and test weapons and defense systems. Trainers and land managers alike realize that the training and testing range must be a realistic and ecologically healthy environment and that training and testing lands must be sustained for long-term use. Sustainment includes planning for and adjusting to natural disturbance and training and/or testing induced disturbance as stressors to the lands. The Army lacks the proper combination of data, protocols, and validated models required to accurately estimate current and predict future land condition status and establish the relationship between training load and land condition to sustain its training resources.

The EDYS model is executable software that contains the scientific information, databases, and protocols necessary to simulate the natural dynamics (fluctuations) of the major plant/soil communities or ecosystems of an installation over temporal and spatial scales of interest to Army trainers and land managers. The model will run simulations of the impact of actual or proposed training disturbance regimes and the recovery process over time scales of 1 week to 100 years 
(or more) and over spatial scales from the species level to landscape levels. The EDYS model provides improved measures and predictions of land condition including species composition and successional dynamics that can be used to identify the relationships between training load and land condition recovery.

EDYS is a powerful tool for support of scenario-based planning analyses. Scenario-based planning may also provide important input for EDYS analyses. Further information about EDYS can be found at:

http://www.shepmill.com/papers/papers.htm

\section{Military Ecological Risk Assessment Framework (MERAF)}

MERAF is a hierarchical framework based on the EPA's Ecological Risk Assessment F ramework, but adapted for military applications. It provides a process for integrated assessment of risks to natural resources from multiple, cumulative, direct, and indirect impacts resulting from training and testing activities.

The MERAF provides a process for integrated assessment of risks to natural resources on military installations. It can be used as the basis for a risk-based management approach to support the military training and testing mission. It is a hierarchical framework consisting of three levels of increasing specificity: programmatic level, activity-specific level, and site-specific level. The programmatic-level framework provides a procedure for assessing risks associated with broad-scale training or testing programs. The activity-specific framework guides analysis of generic risks associated with specific, narrowly-defined training or testing activities, regardless of where the activity takes place. The site-specific framework is for use at a specific facility and environment and defines a process for performing integrated site-specific assessments of multiple activities for riskbased management at that location.

This framework will provide: (1) more efficient use of installation's financial, natural, and cultural resources through the application of an assessment framework in support of risk-based management, (2) less costly and more defensible environmental planning documentation, including Environmental Impact Statements (EISs), Environmental Assessments (EAs), and Integrated Natural Resources Management Plans (INRMPs), and (3) more focused and less costly data collection for documentation, planning, and management.

MERAF can supply important input parameters for scenario-based planning and can provide a risk context within which to evaluate the scenarios produced by a study. Risk factors should be one of the elements taken into consideration in evaluating and choosing a scenario for implementation. 


\section{Technology Transfer/Summary}

This report begins to define the framework by which the Army process of determining how the surrounding non-military lands and the changes in the future will affect the mission of the installation. Forces both inside and outside the installation boundary need to be considered and the likely results of these modeled within reason. This procedure will integrate the best regional land planning technology currently available and will be based on computer modeling techniques using state-of-the-art GIS and Information Management (IM) capabilities. This report reviewed the history, techniques of the discipline, outlined potential users and applications, and discussed the current technology context into which the protocol would fit.

The purpose of this scoping report has been to outline the technology, technical requirements, and possibilities associated with scenario-based planning, and discuss its potential application as a standardized protocol for military installation and MACOM use. The intended use for this report is to assist the Army and DoD to evaluate whether further development of a military-adapted protocol for scenario-based planning would be worthwhile.

In this report, scenario-based planning has been defined and some historical context provided. Questions of how and why the concept can be adapted to the military have been explored. The report also explored unique Army issues, a general concept of the cost associated with scenario-based planning in relationship to the level of detail desired, and the need for standardization so users will be able to approach the model based on a clear user interface.

There are a great many potential users both within the Department of the Army and within the local community. Scenario-based planning has applications in supporting better community relationships over the long term, various regional applications, Native American tribal use negotiations, the management of threatened and endangered species, as well as other natural and cultural resources programs. It can help support the management of military installations as well as coordinate with mobilization planning. In addition, the results of scenario-based planning are useful at higher levels such as MACOMs. The MACOMs may wish to have specific indices included that allow them to compare potential effects between different installations and the communities within which the installations reside. These indices are particularly useful in terms of 
mission planning, encroachment comparisons, and evaluation of potential legal entanglements.

One of the great values of scenario-based planning is the ability to vary the policy scenarios proposed by the different stakeholders so that they may be able to see the likely effects on the land of the actions they may be proposing. The fact that this can be done is a result of the information management technologies that have been developed within the classical scenario-based planning procedure. Currently many of these technologies require a very large investment in hardware and software. However, on certain fronts, the essence of these programs has already been ported to a very manageable personal computer level. In addition to this, the advent of Internet Web technology tends to minimize the question of what hardware the local user needs in order to run a scenario. If each run is submitted via the Internet, the user is no longer limited to the machines available locally. Umbrella software packages providing the user with a single standard interface, such as the Corps of Engineers' LMS, have the potential to allow much easier access to even complicated models such as scenario based planning models. 


\section{Conclusions and Recommendations}

\section{Conclusions}

This scoping study has identified the following:

- The general approach of scenario-based planning shows promise for Army and DoD application to hel $p$ avoid and resolve issues related to encroachment and other regional issues that concern both military installations and their neighbors. The application of this technol ogy can help ensure that DoD's interests and missions play an influential and effective role within the larger sociopolitical processes that shape the futures of regions surrounding installations.

- Benefits can accrue to the Army and DoD by playing a proactive and interactive role as leaders in scenario-based planning efforts in regions where installations are situated.

- The ad hoc application of scenario-based planning to individual installations results in a good but expensive technical information product. It does not necessarily transfer scenario-based planning tools for future installation and MACOM use.

- There is a need to find and apply a less expensive, more generic and standardized approach for scenario-based regional planning in a way that leaves installations and/or DoD centers of expertise with the necessary tools for future applications of the technol ogy.

- Scenario-based planning science and methodology are now maturing and will technically allow the development of a generalized protocol.

- Sophisticated techniques, models, software, computerized capabilities now exist and are under further development within DoD and the civilian sector. These capabilities would support a DoD-focused protocol for scenario-based planning by providing input data and flexible, interactive, web-based modeling environments. At the same time, many of these other capabilities could be put to more powerful use if they were supported by outputs from a scenario-based planning protocol. 


\section{Recommendations}

It is recommended as a result of this scoping study and the conclusions outlined above, that the Army further pursue development of a less expensive, more efficient, and Army-adapted methodology for applying scenario-based planning to installation and MACOM-level requirements. A general concept for a scenariobased protocol, adapted for Army/DoD use, is described in the following paragraphs.

The protocol should be a systematic procedure for:

- conducting scenario-based analyses of potential futures at a regional scale,

- comparing the different scenarios to each other on the basis of user-identified common values, costs, and benefits,

- designing monitoring and follow-up programs to compare projected with actual future events and trends, for ongoing management, and to improve the scenario-based planning process.

The protocol should not be designed and delivered as a stand-alone computerized system. It should be a web-based procedure that is designed to link and interact with other related Army systems currently existing or under development, such as the Land Management System as an umbrella modeling environment. The protocol should also be provided as a set of written guidelines suitable for incorporation into a statement of work.

The protocol should be designed to identify and evaluate potential changes in land use, and the resulting effects on a series of identified values that reside in the environment at the regional scale and that are expressed through land use. Thus, the primary variable in the approach should be Land Use and changes in land use. There are many factors that affect land use, both directly and indirectly, that will need to be built into the protocol to the extent feasible. Using the variable "Land Use" will allow expression of the effects of these different factors using a common metric, language of expression, and mode of representation. Having a common metric or mode of representation will allow interrelationship of the effects of various factors to the fullest extent supported by the current status of knowledge. At a later stage of development, the desirability and feasibility of other primary variables not based on land use could be examined, but for the first stage of development, a focus on land use and changes thereto is recommended.

The Army Protocol should be designed to accomplish the following:

- Provide a logic-based approach for:

- asking the right questions 
- identifying the issues of concern

- designing a site-specific study

- identifying the data, tools, and resources needed to conduct the study

- guiding one through the analysis

- evaluating the results

- presenting the results to stakeholders

- designing an ongoing monitoring/follow-up program.

- Provide access to, or be an application-context for, selected capabilities that will facilitate scenario-based regional land use analyses and land management planning for long-term use by installations and their neighbors. Examples of such capabilities have been discussed in this report.

The protocol development effort should seek to enhance ease of use, including but not limited to the following ways:

- design a user-friendly interface and process for using the protocol (possibly within the context of the LMS environment),

- provide quality metadata and other background information,

- provide user-friendly training materials (including possibly a training workshop curriculum),

- provide a boilerplate Scope of Work to be used if a contractor will be engaged to do the analysis, and

- pursue possibilities for setting up a user support service for the protocol, perhaps in conjunction with other capabilities (such as LMS) with which the protocol is linked.

Another effort, following on this scoping report, will soon be underway. The objective of the new effort is to review the state-of-the-art of competing alternative futures methodologies and demonstrate the feasibility of simpler technology transfer technique(s). The tasks to be accomplished in this effort are:

(a) review the state-of-the-art of scenario-based regional planning methodol ogies that show most likelihood of adaptability to DoD needs;

(b) develop conclusions and recommendations for a general approach or protocol for DoD use, focusing on a regional spatial scale, and a time scale of 20 to 25 years;

(c) select one existing software tool for scenario-based planning based on above review; 
(d) apply the selected software tool to one military installation using existing databases and information, as an example and demonstration of the use of generic software for this purpose;

(e) recommend any modifications to the software tool/approach that suggest themselves as a result of working through the applied example. 


\section{References}

Currie, D.J . 1991. Energy and large-scale patterns of animal and plant species richness. Am. Nat. 137:27-49.

Steinitz, Carl, et al, 1998. Alternative Futures for the Upper San Pedro River Basin, Arizona and Sonora: The Region of F ort Huachuca; poster presented at the 1998 SE RDP Symposium describing work funded by the Department of Defense Legacy Program and conducted by the Harvard Design School, ERDC/CERL, U.S. Army TRADOC, the Desert Research Institute, the University of Arizona, and the Semi-Arid Land Surface/Atmosphere (SALSA) program.

Steinitz, Carl, et al. 1998. Alternative Futures in the Western Galilee, I srael, Harvard Graduate School of Design.

Steinitz, Carl, Michael Binford, Paul Cote, Thomas Edwards, J r., Stephen Ervin, Richard T.T. Forman, CraigJ ohnson, Ross Kiester, David Mouat, Douglas Olson, Allan Shearer, Richard Toth, and Robin Wills. 1996. Landscape Planning for Biodiversity: AlternativeF utures for the Region of Camp Pendleton, CA, produced by the authors under work funded by the DoD/DOE/EPA Strategic Environmental Research and Development Program, and printed by the Harvard Graduate School of Design.

Steinitz, Carl. 1967. Computers and Regional Planning: The DELMARVA Study. Harvard Graduate School of Design.

Stephenson, N.L. 1990. Climatic control of vegetation distribution: the role of water balance. The American Naturalist. 135:649-670. 


\section{Appendix A: Web Materials Search Bibliography}

Strategic, Futures, \& Scenario-Based Planning Papers and Resources:

An Alternative Future for the Region of Camp Pendleton, Graduate School of Design, Fall 1996 Design Studio, Harvard University [Study, Scenario Based Regional Planning Study]

Alternative Futures for the Gartenreich Dessau-Worlitz, Germany, Carl Steinitz and the Graduate School of Design, Harvard University, Cambridge, MA. [Study, Scenario Based Regional Planning Study]

Analyzing Environments and Developing Scenarios for Uncertain Times, James L. Morrison and lan H. Wilson. Originally published in M. W. Peterson, D. D. Dill, L. A. Mets, and Associates (eds.), Planning and Management for a Changing Environment. San Francisco: Jossey-Bass, 1997. [Paper, Scenario Development and Strategic Planning]

Anticipatory Management Tools for the 21st Century, William C. Ashley and James L. Morrison. Originally published in the Futures Research Quarterly, Summer 1996, 12(2), pp. 35-50, World Future Society, Bethesda, MD. [Paper, Scenario Development and Strategic Planning]

Anticipatory Management: Tools for Better Decision Making, William C. Ashley and James L. Morrison. Originally published in The Futurist, September-October 1997, pp. 47-50. [Paper, Scenario Development and Strategic Planning]

Biodiversity and Landscape Planning: Alternative Futures for the Region of Camp Pendleton, California, Graduate School of Design, Harvard University, Cambridge, MA. [Study. Scenario Based Regional Planning Study]

Card, Dr. Karen, Adult and Higher Education Program, Division of Educational Administration, School of Education, University of South Dakaota, 201 A Delzell , 414 E. Clark St., Vermillion, SD 57069. Phone: (605) 677-6076,

Email:kcard@usd.edu. [Educator, Strategic Planning]

The Center for Futures Research, St. Gallen, St. Gallen, Switzerland and the University of St. Gallen. (St. Gallen Zentrum für Zukunftsforschung AG, Dufourstrasse 28, CH-9000, St. Gallen Switzerland. Phone:

41.071.244.28.16, FAX: 41.071.244.13.10) [University Research Center, Scenario Development and Strategic Planning]

Contextual Planning, Analyzing Environments and Developing Scenarios for Uncertain Times, Dr. Karen Card, University of South Dakota, Vermillion, SD. [Training Program, Environmental Scanning and Scenario Development]

Decision Analysis Society of INFORMS, Fuqua School of Business, Duke University, Durham, NC. Promotes development and use of logical methods for the improvement of public and private enterprise decision-making. Methods include models for decision-making under conditions of uncertainty or multiple objectives; risk analysis and assessment techniques; experimental and descriptive studies of decision-making behavior; economic analysis of competitive and strategic decisions; techniques for facilitating decision-making by groups; and computer modeling software and expert systems for decision support. The Fuqua School of Business, Duke University, Box 90120, Durham, NC 27708-0120. Phone: (919) 660-7700, FAX: (919) 684-2818. [University Research Center, Environmental Scanning, Scenario Development and Strategic Planning]

Environmental Scanning, James L. Morrison, Originally printed as a chapter in "A Primer for new Institutional Researchers," M. A. Whitely, J. D. Porter, and R. H. Fenske (Eds.), A primer for new institutional researchers, Tallahassee, Florida: The Association for Institutional Research, 1992. [Paper, Processes for identification of change/trends]

FAQs About Scenario-Based Planning, by Paul S. Forbes, Chairman, The Forbes Group and Bruce Butterfield, CAE, President, The Forbes Group, (C 1994. [Paper, Corporate Scenario Based Strategic Planning] 
The Futures Group (TFG), Subsidiary of Deloitte Consulting, 185 Asylum Street, Floor 33, Hartford, CT 06103 , (860) 280-3000. EMail: cathyjohnson@dttus.com. [Consultant, Strategic Planning]

Futures Research and the Strategic Planning Process - Implications for Higher Education, James L. Morrison, William L. Renfro and Wayne I. Boucher, ASHE-ERIC Higher Education Research Reports, ERIC Clearinghouse on Higher Education, 1984. [Paper, Scenario Based Strategic Planning for Educators]

Goldberg Report: A Leadership Agenda, Appendix D: Boston Scenarios, Scenario text, Patricia Brady, Appendix adapted from "Boston Scenarios" by David Garvey, Fall/Winter 1997 issue, New England Nonprofit Quarterly, Tufts University, Medford, MA. [Paper, Boston Area Planning Scenario Development]

Global Business Network (GBN), Global Business Network, P. O. Box 8395, Emeryville, CA 94662, Phone: (510) 547-6822, FAX: (510) 547-8510, Email: wws@gbn.org. A 'network' of organizations and individuals committed to reperceiving the present in order to anticipate the future and better manage strategic response. [Association, Corporate Scenario Based Strategic Planning]

GBN Scenario Planning - Using Scenarios, a brief guide to scenarios and the process of creating them, Global Business Network (GBN). [Paper, Corporate Scenario Based Strategic Planning]

GBN Scenario Planning - Scenario Thinking, reports of actual scenario projects, Global Business Network (GBN). [Papers, Corporate Scenario Based Strategic Planning]

Green Mountain Institute for Environmental Democracy (GMIED), 104 E. State St., Montpelier, VT 05602, Phone: (802) 229-6070, FAX: (802) 229-6076, gmied@gmied.org. [Association, Environmental Planning/Comparative Risk Assessment]

"Hammers, Screwdrivers, and Wrenches: Tools for Building More Effective Local Environmental Management", SYNERGY, January/February 1998, Green Mountain Institute for Environmental Democracy (GMIED). [Paper, Tools for environmental management]

HORIZON, University of North Carolina - Chapel Hill, Web Resources for educators' strategic visioning and planning). [Education Association, Scenario Based Strategic Planning for Educators]

HORIZON - Workshops and Seminars, Tools for environmental scanning, vulnerability/opportunity audits, issues management, and scenario development, HORIZON, University of North Carolina - Chapel Hill. [Education Association, Scenario Based Strategic Planning for Educators]

"How to Build Scenarios", by Lawrence Wilkinson, Cofounder and president, Global Business Network (GBN), Copyright 1993-98 The Condé Nast Publications Inc. and 1994-98 Wired Digital Inc. [Paper, Scenario Development Methodologies]

Institute for the Future, independent, nonprofit research firm specializing in long-term forecasting, alternative futures scenarios, and impact assessments, 2740 Sand Hill Road, Menlo Park, CA 94025-7097. Phone: (650) 854-6322, FAX: (650) 854-7850. [Association, Corporate Scenario Based Strategic Planning]

Limiting Urban Futures, The defects of scenario-based planning, Paul Treanor. [Paper, Futurist, Thought and Theory]

Nickols, Frederick W., Executive Director, Strategic Planning \& Management Services, Educational Testing Service, Mail Stop 09-C, Princeton, NJ 08541. Phone: (609) 734-5077, FAX: (609) 734-5590, EMail: fnickols@ets.org or senior consultant, The Distance Consulting Company, 108 Endsleigh Court, Robbinsville, NJ 08691. Phone: (609) 490-0095, EMail: nickols@worldnet.att.net. [Consultant, Strategic Planning]

The Practicality of Scenario-Based Planning, by Charles Thomas, Director of Scenario-Based Planning, The Futures Group (TFG). [Paper, Corporate Scenario Based Strategic Planning]

RAND Corporation, 1333 H Street, N.W., Washington, DC 20005-4707, Phone: (202) 296-5000. [Consultant, Strategic Planning]

RAND Europe, Newtonweg 1, Leiden, The Netherlands, 2333, Phone: 011-31-71-524-5151. [Consultant, Strategic Planning]

Scenario Based Planning Model Infrastructure and Transportation Analyses, RAND Europe. [Planning Study, Scenario Based]

Scenario Based Planning (STP), Basic process and links, The Center for Futures Research, St. Gallen, Switzerland. [Paper/Pointers to Scenario Based Planning Web Sites] 
Six Question Study Framework, Carl Steinitz, Graduate School of Design, Harvard University, Cambridge, MA. [Scenario Based Planning Methodology]

Steinitz, Carl, Department of Landscape Architecture, Alexander and Victoria Wiley Professor of Landscape Architecture and Planning, Graduate School of Design, Harvard University, Gund Hall, Room 415, 48 Quincey Street, Cambridge, MA 02138. Phone: (617) 495-5419, FAX: (617) 495-5015, EMail: csteinitz@gsd.harvard.edu. [Educator/Researcher, Urban \& Regional Planning]

The Strategic Management Response to the Challenge of Global Change, James L. Morrison and lan H. Wilson. Published in Didsbury, Howard (Ed.). Future Vision, Ideas, Insights, and Strategies. Bethesda, MD: World Future Society, 1996. [Paper, Strategic Planning]

SYNERGY, Green Mountain Institute for Environmental Democracy (GMIED). GMI Newsletter, reviews of environmental planning and management tools. [Newsletter, Environmental management issues]

Twiss, Robert, Ph.D., M.S., Professor in the Graduate School, REGIS/CEDR, The Department of Landscape Architecture and Environmental Planning, College of Environmental Design, University of California, Berkeley, 360 Wurster Hall, \#2000, Berkeley, CA 94720-2000. Phone: (510) 308-0331, FAX: (510) 643-5571, EMail: twiss@regis.berkeley.edu. [Educator/Researcher, Environmental Planning]

Using Scenarios to Take Control of Your Association's Destiny, ASAE Management Conference, August 10, 1996. [Agenda/Process, Corporate Scenario Based Strategic Planning Conference]

\section{Futurists (General)}

Ashley, William C., President, Ashley \& Associates. Adjunct Professor, Integrated Marketing Communication Graduate Program, Medill School of Journalism, Northwestern University, 1845 Sheridan Road, Evanston, IL 60208-2102. Phone: (847) 491-5228, FAX: (847) 467-2319. [Futurist, Thought and Theory]

Future.Com, by Glen Hiemstra, Hiemstra International, POB 2349, Redmond, WA 98073-2349, Phone: 425-5761441, EMail: ghiemstra@futurist.com. [Futurist, Thought and Theory]

Factasia, and Factasia Index, Roger Bishop Jones Limited, 7 Blamire Drive, Binfield, Berkshire RG42 4UN, England, Phone/FAX: 01344 642507, EMail: mailto:rbjones@cybercom.net. [Futurist, Thought and Theory]

Factasia - The Future, Roger Bishop Jones Limited. [Futurist, Thought and Theory]

The Future of Futures. [Futurist, Thought and Theory]

The Futurist, World Future Society, Bethesda, MD [Futurist, Thought and Theory]

Document Index, Paul Treanor [Futurist, Thought and Theory]

Morrison, James L., School of Education, CB\#3500, Peabody Hall, University of North Carolina, Chapel Hill, NC 27599-3500, Phone: (919)/962-2517, morrison@unc.edu. [Futurist, Thought and Theory]

Wilson, Ian H., Principal, Wolf Enterprises, San Rafael, CA, Jason415xx@aol.com [Futurist, Thought and Theory]

World Future Society, 7910 Woodmont Avenue, Suite 450, Bethesda, MD. Phone: (800) 989-8274 or (301) 6568274, FAX: (301) 951-0394, EMail: echard@wfs.org. [Futurist, Thought and Theory]

\section{Military Strategic and Scenario Based Planning}

Center for Strategy and Technology, The United States Air Force Air War College, William C. Martel, Director, 325 Chennault Circle, Maxwell AFB, Montgomery, AL 36112. Phone: (334) 953-2384, EMail:

wmartel@max1.au.af.mil. [USAF, Strategic Planning for National Defense]

Essay on Strategy XIV- Beyond the Bottom-Up Review, Colonel Mark A Gunzinger, U. S. Air Force. Written while Lieutenant Mark A Gunzinger, U. S. Air Force, was a student at the National War College, 1996. [Paper, scenario based defense strategic planning processes/methodologies]

Future Planning: Strategies for ADF and Army, Jill Dobson, Graduate Administrative Assistant, Directorate of Army Research and Analysis (Australian Army) Land Warfare Studies Centre, Duntroon, Australia. [Paper, Australian Army, Strategic Planning for National Defense] 
Institute for National Strategic Studies, National Defense University, Hans A. Binnendijk, Director, Phone: (202) 6853838, EMail: binnendijkh@ndu.edu, Marshall Hall, 300 5th Avenue, Ft. McNair, Washington, DC 20319-5066. [DoD, Strategic Planning for National Defense]

National War College, RADM Thomas F. Marfiak, USN, Commandant, Ft. McNair, Washington, DC 20319. [DoD, Leadership training for national security strategy and policy process]

Strategic Studies Institute, U. S. Army War College, Carlisle Barracks, Carlisle, PN 17013-5050. [DA, Strategic Planning for National Defense]

\section{Sources, Pointers \& Bibliographies}

Assorted Scenario Planning Links, Brian J. Reithel, Ph.D., The University of Mississippi, School of Business Administration, Oxford, MS, 1998. [Pointers to Internet 'Scenario Planning' Web Sites]

Basic Research Resources for City \& Regional Planning, Environmental Design Library, University of California, Berkeley, Berkeley, CA. [Pointers to Planning Internet Resources]

Business \& Strategic Planning Bibliography, Fred Nickols, Educational Testing Service, Princeton, NJ.

Cyburbia, (formerly PAIRC - "Planning and Architecture Internet Resource Center"), School of Architecture, State University of New York at Buffalo, Buffalo, NY. [Pointers to Planning and Architecture Internet Resources]

Factasia - General Future Resources, Roger Bishop Jones Limited. [Pointers to Internet 'Futures Oriented' Web Sites]

Factasia - Scenario Planning, Roger Bishop Jones Limited. [Pointers to Internet 'Scenario Planning' Web Sites]

The Future of Futures. [Pointers to Internet 'Futures Oriented' Web Sites]

GBN Scenario Planning, Global Business Network (GBN). [Pointers to Internet 'Scenario Planning' Web Sites/Resources]

GBN Scenario Planning - Scenario Bibliography, Global Business Network (GBN).

Links to web sites related to rural development, Massachusetts Rural Development Council, Inc., University of Massachusetts, Amherst, MA. [Pointers to Rural Development Sites]

Planning Resource Directory, School of Architecture, State University of New York at Buffalo, Buffalo, NY. [Pointers to Planning and Architecture Internet Resources]

Scenario Based Planning (STP), Basic process and links, The Center for Futures Research, St. Gallen, Switzerland. [Paper/Pointers to Scenario Based Planning Web Sites]

Systems Thinking Practice (STP), interactive 'Yellow Pages' directory to Systems Thinking and related activities on the Web, The Center for Futures Research, St. Gallen, Switzerland. [Pointers to Systems Thinking Web Sites]

Watershed Planning Information On-line: Information for Estuary / Watershed Planning, Robert Twiss, University of California, Berkeley, Berkeley, CA. [Pointers to Watershed Planning]

\section{Infrastructure Analyses, Studies, Models}

Transportation

Albuquerque metropolitan area Unified Planning Work Program (UPWP) for Intermodal Transportation PlanningFiscal Year 1995, Federal Transit Administration (FTA). [Transportation Study Including Scenario Development]

Extending the Activity-Based Approach to Include Mobility, Lifestyle and Land Use Decisions, Moshe Ben-Akiva, Massachusetts Institute of Technology, Cambridge, MA. [Professor of Civil \& Environmental Engineering; Director, Intelligent Transportation Systems Program, MIT 1-181, Cambridge MA 02139. Phone: (617) 253-5324; FAX: (617) 253-0082; EMail: MBA@MIT.EDU] [Research, Activity-Based Travel Demand Forecasting Model]

Impact Analysis of Spatial Data Aggregation on Transportation Forecasted Demand: A GIS Approach, Chengri Ding, Department of Urban \& Regional Planning, University of Illinois, Urbana-Champaign, IL, (1994), p362-375, copyright Urban and Regional Information Association (URISA). Phone: (217)-244-5366, FAX: (217)-244-1717, EMail: ding@lucy.gis.uiuc.edu. [Research, GIS based transportation planning analysis] 
MIT Center for Transportation Studies, Massachusetts Institute of Technology, Cambridge, MA. Phone: (617) 2587267, FAX: (617) 253-4560, Email: cts-www@mit.edu. MIT is designated as lead University for the U. S. Department of Transportation, Transportation Centers Program (UTC). [University/Governmental Transportation Planning]

Morse/Bethel Connector Study, MORPC, Columbus, OH. [Transportation Study Including Scenario Development]

A New Generation of Regional Strategic Transportation Plans, By Joseph Sussman, JR, Massachusetts Institute of Technology, Cambridge, MA. , [Professor of Civil and Environmental Engineering; Director, AAR Affiliated Lab (MIT 1-163, Cambridge MA 02139. Phone: (617) 253-4430; FAX: (617) 258-5942, EMail: SUSSMAN@MIT.EDU] [Research, scenario-based strategic plans for transportation planning].

Review of the Transportation Planning Process in the Denver Metro Area, Federal Transit Administration (FTA), http://www.fta.dot.gov/. [Transportation Study Including Scenario Development]

Review of the Transportation Planning Process in the Kansas City Metro Area, Federal Transit Administration (FTA). [Transportation Study Including Scenario Development]

Urban Transportation Planning for the Next Century, Moshe Ben-Akiva, Massachusetts Institute of Technology, Cambridge, MA. [Professor of Civil \& Environmental Engineering; Director, Intelligent Transportation Systems Program, MIT 1-181, Cambridge MA 02139. Phone: (617) 253-5324; FAX: (617) 253-0082; EMail: MBA@MIT.EDU] [Research, Urban Transportation Modeling Capability Development]

U. S. Department of Transportation, Transportation Centers Program (UTC). Includes state universities of Connecticut, Maine, Massachusetts, New Hampshire, Rhode Island and Vermont, and Harvard University. [University/ Governmental Transportation Planning]

\section{Governmental Planning Groups/Associations}

Mid-Ohio Regional Planning Commission (MORPC), Voluntary association of 39 Ohio governments, William C. Habig, Executive Director, 285 E. Main St., Columbus, OH 43215. [Government Planning commission]

Massachusetts Rural Development Council, Inc., 406 Goodell Building, University of Massachusetts, Amherst, MA 01003. Phone: (413) 545-4404, FAX: (413) 545-1795, EMail: info@mrdc.org. [Government Planning commission]

The Travel Model Improvement Program (TMIP), The Department of Transportation and The U.S. Environmental Protection Agency. [Government Group, Transportation analysis]

\section{Urban, Regional and Environmental Planning at Educational Institutions/Research}

Applied Environmental Geographic Information Science Research Lab (AEGIS), CEDR, College of Environmental Design, University of California, Berkeley, 202 Wurster Hall, \#2000, Berkeley, CA 94720-2000. EMail: aegis@ced.berkeley.edu. [University Research Center, Environmental Planning]

The Center for Environmental Design Research (CEDR), College of Environmental Design, University of California, Berkeley, 390 Wurster Hall, \#1839, Berkeley, CA 94720-1839. Phone: (510) 642-2896. [University Research Center, Environmental Planning]

College of Environmental Design, University of California, Berkeley, 390 Wurster Hall, \#1839, Berkeley, CA 947201839. Phone: (510) 642-2896. [University Research Center, Environmental Planning]

The Department of City and Regional Planning, College of Environmental Design, University of California, Berkeley, 228 Wurster Hall, \#1850, Berkeley, CA 94720-1850. Phone: (510) 642-3256, FAX: (510) 642-1641, EMail: dcrpinfo@ced.berkeley.edu. [University Department, Urban \& Regional Planning]

The Department of Landscape Architecture and Environmental Planning, College of Environmental Design, University of California, Berkeley, 206 Wurster Hall \#2000, Berkeley, CA 94720-2000. Phone: (510) 642-2965, FAX: (510) 643-6166, EMail: kris@uclink.berkeley.edu. [University Department, Environmental Planning]

Environmental Simulation Laboratory, Peter Bosselmann, Professor of Urban Design, The Department of City and Regional Planning, College of Environmental Design, University of California, Berkeley, 228 Wurster Hall, \#1850, Berkeley, CA 94720-1850. Phone: (510) 642-3256, FAX: (510) 642-1641, EMail: dcrp-info@ced.berkeley.edu. [University Research Center, Environmental Planning] 
Institute of Urban and Regional Development (IURD), College of Environmental Design, University of California, Berkeley, 316 Wurster Hall, \#1870, Berkeley, CA 94720-1870. Phone: (510) 642-4874, FAX: (510) 643-9576. [University Research Center, Urban \& Regional Planning]

Regional Economic Forecasting and Simulation, University Center for Social and Urban Research (UCSUR), Urban and Regional Planning Program, Graduate School of Public \& International Affairs, University of Pittsburgh, Pittsburgh, PA. [University Research Center, Urban \& Regional Planning]

Research Program in Environmental Planning and GIS (REGIS), CEDR, College of Environmental Design, University of California, Berkeley, 390 Wurster Hall, \#1839, Berkeley, CA 94720-1839. Phone: (510) 642-9205, FAX: (510) 643-5571, EMail: regis@regis.berkeley.edu. [University Research Center, Environmental Planning]

The UC Davis Tahoe Research Group, Department of Environmental Science and Policy, Division of Environmental Studies, University of California, Davis, 2132 Wickson Hall, Davis, CA 95616. Charles Goldman, PhD., Director, Office: 3104D Wickson Hall, Phone: (916) 752-1557, FAX: (916) 752-3350, Email: crgoldman@ucdavis.edu. [University Research Center, Environmental Planning]

University Center for Social and Urban Research (UCSUR), Urban and Regional Planning Program, Graduate School of Public \& International Affairs, Third Floor Forbes Quadrangle, University of Pittsburgh, Pittsburgh, Pa. 15260. [University Research Center, Urban \& Regional Planning]

The Yale Urban Design Workshop and Center for Urban Design Research (UDW), Michael R. Haverland, Assistant Professor (Adjunct) in Architectural Design and Alan J. Plattus, Associate Dean of the School of Architecture, CoDirectors, Yale School of Architecture, New Haven, CT. [University, Urban \& Regional Planning] 


\title{
Appendix B: APA List of Accredited American University Planning Programs
}

\author{
http://www.netins.net/showcase/pab fi66/accschl2.htm
}

\begin{abstract}
Cyburbia, Resource Directory
\end{abstract}
http://www.arch.buffalo.edu/cgi-bin/pairc/sch_plan

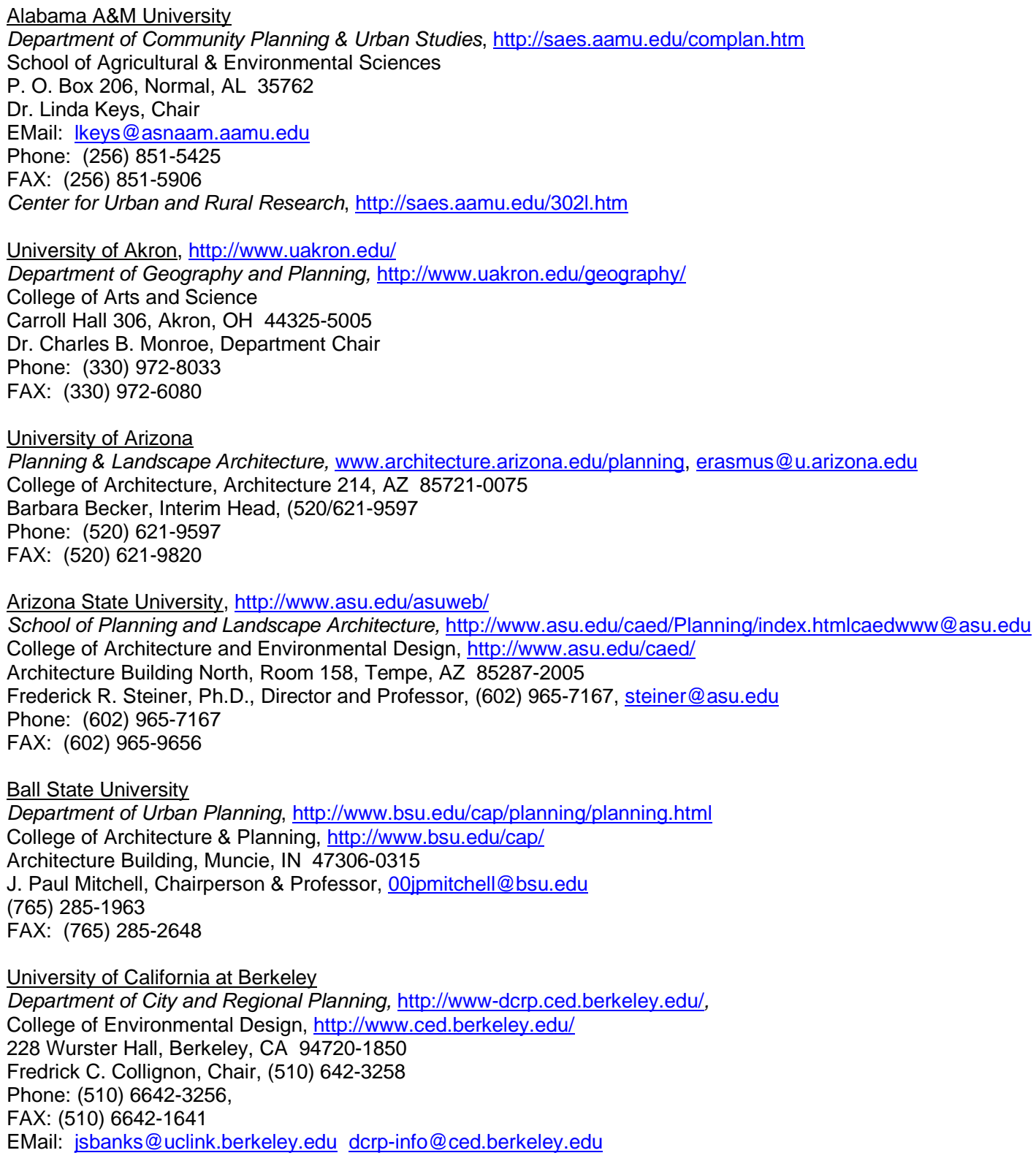


University of California, Irvine

Department of Urban and Regional Planning, http://www.seweb.uci.edu/depart/urp home.html

School of Social Ecology, http://www.seweb.uci.edu/

Social Ecology I, Room 202, Irvine, CA 92697-7075

Scott Bollens, Ph.D., Associate Professor \& Chair, (949) 824-7696, sabollen@uci.edu

Phone: (949) 824-3480

FAX: (949) 824-2056

University of California, Los Angeles

Department of Urban Planning, http://www.sppsr.ucla.edu//dup/home dup.htm

School of Public Policy and Social Research, http://www.sppsr.ucla.edu/SPPSR.HTM

3250 Public Policy Building, Box 951656, Los Angeles, CA 90095-1656

Donald Shoup, Ph.D., Professor and Chair, (310) 825-5705, FAX: (310) 206-5566, shoup@ucla.edu

Phone: (310) 825-8957/4025

FAX: (310) 206-5566

California Polytechnic State University, San Luis Obispo

City and Regional Planning Department, http://www.calpoly.edu/ crp/index.html

College of Architecture \& Environmental Design

1 Grand Avenue, San Luis Obispo, CA 93407

William Siembieda, Department Head

Phone: (805) 756-1111

FAX: (805) 756-1340

EMail: crp@oboe.calpoly.edu

California State Polytechnic University, Pomona

Department of Urban and Regional Planning, http://www.csupomona.edu/ urp/

College of Environmental Design

3801 West Temple Avenue, Pomona, CA 91768-4048

Richard W. Willson, Department Chair and Professor, (909) 869-2701, RWWILLSON@CsuPomona.Edu

Phone: (909) 869-2688

FAX: (909) 869-4688

University of Cincinnati

School of Planning, http://www.daap.uc.edu/planning/default.html

College of Design, Architecture, Art, and Planning, http://www.daap.uc.edu/

Aronoff Center for Design, P. O. Box 210016, Cincinnati, OH 45221-0016

David Edelman, PhD, Professor and Director, (513) 556-0210, David.Eedelman@uc.edu

Phone: (513) 556-4943

FAX: (513) 556-1274

Clemson University, http://www.clemson.edu/

Department of Planning and Landscape Architecture, http://hubcap.clemson.edu/aah/pla/

College of Architecture, Arts and Humanities, http://hubcap.clemson.edu/aah/toc/index.htm

121 Lee Hall, Box 340511, Clemson, SC 29634-0511

Barry C. Nocks, Coordinator, (864) 656-4094, nocks2@clemson.edu

Phone: (864) 656-3926

FAX: (864) 656-7519

Cleveland State University

Master of Urban Planning, Design, and Development (MUPDD), http://urban.csuohio.edu/ ustweb/mupdd.htm

Maxine Goodman Levin College of Urban Affairs, http://urban.csuohio.edu/index.htm, ustweb@urban.csuohio.edu

1737 Euclid Avenue, UB112E, Cleveland, OH 44115

Mittie Olion Chandler, Director, (216) 687-3861, lurie@wolf.csuohio.edu

Phone: (216) 687-2136

FAX: (216) 687-9291

The Urban Center Online, http://urban.csuohio.edu/ ucweb/index.htm

Dr. Camilla Stivers, Ph.D., Albert A. Levin Chair of Urban Studies and Public Service

University of Colorado, at Denver

Urban and Regional Planning Program, http://www.cudenver.edu/public/AandP/departments/plan/main2.html

College of Architecture and Planning, http://www.cudenver.edu/public/AandP/

Campus Box 126, P.O. Box 173364, Denver, CO 80217-3364

Raymond G. Studer, Department Chair, Phone: (303-556-3479 (Denver); 303-492-7434 (Boulder); EMail: studerr@spot.colorado.edu.

Phone: (303) 556-4867

FAX: (303) 556-3687

Columbia University

Program in Urban Planning, http://www.arch.columbia.edu/Degrees/UP/index.html

Graduate School of Architecture, Planning, and Preservation, http://www.arch.columbia.edu

1172 Amsterdam Avenue, Avery Hall 413A, New York, NY 10027 
Lionel McIntyre, Director, (212) 854-3513

FAX: (212) 864-0410

EMail: Icm3@columbia.edu

Cornell University, http://www.cornell.edu/

Department of City and Regional Planning, http://inet.crp.cornell.edu/

College of Architecture, Art, and Planning, http://www.aap.cornell.edu/aap.htm

105 West Sibley Hall, Ithaca, NY 14853

John Forester, Chair, (607) 255-5179, iff1@cornell.edu

Phone: (607) 255-4331

FAX: (607) 255-1971

Eastern Michigan University

Urban and Regional Planning Program, http://www.emich.edu/public/geo/urp.html

Department of Geography and Geology, http://www.emich.edu/public/geo/welcome.html

College of Arts and Sciences

Strong Hall, Ypsilanti, MI 48197-2219

Norman Tyler, Director, (734) 487-8656, FAX: (734) 487-6979, geo tyler@online.emich.edu

Eastern Washington University, http://www.ewu.edu/Home.html

Department of Urban \& Regional Planning, http://www.cbpa.ewu.edu/ planning/

College of Business \& Public Administration, http://www.cbpa.ewu.edu/

668 N. Riverpoint Blvd., Suite A, Spokane, WA 99202-1660

Richard G. Winchell, Chair, (509) 358-2223, dwinchell@ewu.edu

Phone: (509) 358-2230

FAX: (509) 358-2267

University of Florida

Department of Urban and Regional Planning, http://www.arch.ufl.edu/urp/index.html

College of Architecture

431 ARCH Building, P.O. Box 115706, Gainesville, FL 32611-5706

Prof. Jay M. Stein, Chairman, 352) 392-0997 x425, jmstein@nervm.nerdc.ufl.edu

Phone: (352) 392-0997 x423

FAX: (352) 392-3308

Florida Atlantic University

Department of Urban \& Regional Planning, http://www.fau.edu/divdept/cupa/depts/urp.htm

College of Urban \& Public Affairs, http://www.fau.edu:80/divdept/cupa/homepage.htm

Askew Tower, 220 SE 2nd Avenue, Fort Lauderdale, FL 33301

Dennis E. Gale, Professor and Department Chair, Ph.D., (954) 762-5653, gale@fau.edu

Phone: (954) 762-5652

FAX: (954) 762-5673

Florida State University

Department of Urban and Regional Planning, http://www.fsu.edu/ durp/

College of Social Sciences

311 Bellamy Building, Tallahassee, FL 32306-2280

Charles Connerly, Chairperson

Phone: (850) 644-4510

FAX: (850) 644-6041

Email: durp@coss.fsu.edu

Georgia Institute of Technology

Graduate City Planning Program, http://murmur.arch.gatech.edu/cp/

College of Architecture

245 Fourth Street, NW, Room 204, Atlanta, GA 30332-0155

Steven P. French, Director, steve.french@arch.gatech.edu

Phone: (404) 894-2350

FAX: (404) 894-1628

Harvard University

Department of Urban Planning and Design, http://www.gsd.harvard.edu/depts/upddept/

Graduate School of Design, http://www.gsd.harvard.edu/

48 Quincy Street, Room 312, Cambridge, MA 02138

Alex Krieger, Chairman, fkrieger@gsd.harvard.edu

Phone: (617) 495-9571

FAX: (617) 496-1292

University of Hawaii at Manoa

Department of Urban and Regional Planning, http://www.durp.hawaii.edu/

College of Social Sciences 
SSB Porteus Hall 107, 2424 Maile Way, Honolulu, HI 96822

Karl E. Kim, Professor and Chair, karlk@hawaii.edu

Chair, (808) 956-6865

Phone: (808) 956-7381

FAX: (808) 956-6870

Hunter College, City University of New York

Department of Urban Affairs and Planning, http://maxweber.hunter.cuny.edu/urban/, urban@hunter.cuny.edu 695 Park Avenue, Room 1611, New York, NY 10021

William J. Milczarski, Ph.D., Director, (212) 772-5601, wjmhc@cunyvm.cuny.edu

Phone: (212) 772-5518

FAX: (212) $772-5593$

University of Illinois at Chicago

Urban Planning and Policy Program, http://www.uic.edu/cuppa/upp/

College of Urban Planning \& Public Affairs, http://www.uic.edu/cuppa/upp/, upp@uic.edu

412 S. Peoria Street (M/C 348), Chicago, IL 60607-7065

Curtis R. Winkle, Director and Associate Professor, 312) 996-2155

Phone: (312) 996-5240

FAX: (312) 413-2314

University of Illinois, Urbana-Champaign

Department of Urban \& Regional Planning, http://www.urban.uiuc.edu/

College of Fine and Applied Arts

111 Temple Buell Hall, MC 619, 611 Taft Drive, Champaign, IL 61820

Christopher Silver, Professor and Head, (217) 244-5400

Phone: (217) 333-3890

FAX: (217) 244-1717

EMail: gfisher@uiuc.edu

University of lowa

Graduate Program in Urban and Regional Planning, http://www.uiowa.edu/ urp/

347 Jessup Hall, lowa City, IA 52242-1316

John W. Fuller, Chair, (319)-335-0038, Fax: (319)-335-3330, john-w-fuller@uiowa.edu

Phone: (319) 335-0032

FAX: (319) 335-3330

lowa State University

Department of Community and Regional Planning, http://www.public.iastate.edu/ design/crp/crp.html

College of Design, http://www.design.iastate.edu/

126 College of Design, Ames, IA 50011-3095

Riad G. Mahayni, Professor \& Chair, (515) 294-8525, rmahayni@iastate.edu

Phone: (515) 294-8958

FAX: (515) 294-4015

University of Kansas

Urban Planning Program, http://www.arce.ukans.edu/urban/urban.htm, ubpl@ukans.edu

School of Architecture and Urban Design, http://www.arce.ukans.edu/scharch/scharch.htm

317 Marvin Hall, Lawrence, KS 66045

Eric J. Strauss, Chair, (785) 864-3176

Phone: (785) 864-4184

FAX: (785) 864-5301

Kansas State University

Department of Landscape Architecture/Regional \& Community Planning, http://aalto.arch.ksu.edu/lar/

College of Architecture, Planning \& Design, http://aalto.arch.ksu.edu/

302 Seaton Hall, Manhattan, KS 66506

Dan Donelin, Head and Professor, (785) 532-5961, dandon@ksu.edu

Phone: (785) 532-5961

FAX: (785) 532-6722

University of Maryland at College Park

Program of Urban Studies and Planning, http://www.bsos.umd.edu/ursp/

School of Architecture, http://www.inform.umd.edu:8080/EdRes/Colleges/ARCH

Caroline Hall Room \#01000C, College Park, MD 20742-9150

Marie Howland, Director, mhowland@bss2.umd.edu

Phone: (301) 405-6791

FAX: (301) 314-9897

University of Massachusetts at Amherst 
Department of Landscape Architecture \& Regional Planning, http://www-unix.oit.umass.edu/ /arp/ College of Food \& Natural Resources

109 Hills North, Amherst, MA 01003-4010

Jack Ahern, Head, (413) 545-6632, jfa@larp.umass.edu

Phone: (413) 545-2255

FAX: (413) 545-1772

Massachusetts Institute of Technology

Department of Urban Studies \& Planning, http://web.mit.edu/dusp/www, dusp-web@mit.edu

School of Architecture and Planning, http://sap.mit.edu/

77 Massachusetts Avenue, Bldg. 7, No.337, Cambridge, MA 02139

Bishwapriya (Bish) Sanyal, PhD, Chair, (617) 253-3270, FAX: (617) 253-2654, sanyal@mit.edu

Phone: (617) 253-2122

FAX: (617) 253-2654

University of Memphis

Graduate Program in City and Regional Planning

226 Johnson Hall, Memphis, TN 38152

Gene Pearson, Director, gpearson@cc.memphis.ed

Phone: (901) 678-2161

FAX: (901) 678-4162

Regional Economic Development Center, http://planning.memphis.edu/redcplan/

University of Michigan

Urban \& Regional Planning Program

College of Architecture and Urban Planning, http://www.caup.umich.edu/, caup@umich.edu

2000 Bonisteel Boulevard, Ann Arbor, Ml 48109-2069

Margaret E. Dewar, Chair, (734) 763-2528

Phone: (734.764.1300

FAX: (734) 763-2322

EMail: medewar@umich.edu

Michigan State University

Urban and Regional Planning Program, http://www.ssc.msu.edu/ urp/, urp@pilot.msu.edu

Department of Geography

College of Social Science

201 UPLA Building, East Lansing, MI 48824-1221

June M. Thomas, Director, (517) 355-1696, thomasj@pilot.msu.edu

Programs 517) 353-9054

FAX: (517) 355-7697

University of Minnesota

Master of Urban and Regional Planning Program, http://www.hhh.umn.edu/gpo/planning/courses/

Hubert H. Humphrey Institute of Public Affairs, http://www.hhh.umn.edu/

301 Nineteenth Avenue South, Minneapolis, MN 55455

Professor Richard Bolan, Director, (612) 625-8092, dbolan@hhh.umn.edu

Phone: (612) 625-8092

FAX: (612) 625-3513

Morgan State University

Graduate Program in City \& Regional Planning, http://www.morgan.edu/academic/schools/archit/profes.htm Institute of Architecture \& Planning, http://www.morgan.edu/academic/schools/archit/archit.htm

1700 E. Cold Spring Lane \& Hillen Road, Jenkins Building 334, Baltimore, MD 21251

Siddhartha Sen, Ph.D., Program Coordinator, (410) 319-3208, ssen@morgan.edu

Phone: (410) 319-3225

FAX: (410) 319-3786

University of Nebraska-Lincoln, http://www.unl.edu/

Department of Community \& Regional Planning, http://www.unl.edu/archcoll/front\%20page/CRP.htm

College of Architecture, http://www.unl.edu/archcoll/index.html

302 Architecture Hall, P. O. Box 880105, Lincoln, NE 68588-0105

Gordon P. Scholz, Chairman, (402) 472-9284, gscholz@unlinfo.unl.edu

Phone: (402) 472-9280

FAX: (402) 472-3806

University of New Mexico

Community and Regional Planning Program, http://www.unm.edu/ saap/Programs/crp/GR/overview.html, crp@unm.edu

School of Architecture and Planning, http://www.unm.edu/ saap/

2414 Central Avenue, S.E., Albuquerque, NM 87131

James R. Richardson, Interim Dean, (505) 277-6460

Claudia Isaac, Director, (505) 277-5050 
Phone: (505) 277-4847

FAX: (505) 277-0076

University of New Orleans, http://www.uno.edu/

Urban and Regional Planning Program, http://www.uno.edu/ cupa/murp.html

College of Urban \& Public Affairs, http://www.uno.edu/ cupa/, cupa@uno.edu

New Orleans, LA 70148

Jane S. Brooks, Coordinator, jsbrooks@uno.edu

Phone: (504) 280-6278

FAX: (504) 280-6272

New York University

Program in Urban Planning

Robert F. Wagner Graduate School of Public Service, http://www.nyu.edu/wagner/

4 Washington Square North, New York, NY 10003-6671

Rae Zimmerman, Ph.D., Director and Professor, (212) 998-7432, zimmrmnr@is2.nyu.edu

Phone: (212) 998-7400

FAX: (212) 995-3890

University of North Carolina-Chapel Hill

Department of City and Regional Planning, http://www.unc.edu/depts/dcrpweb/index.html

College of Arts and Sciences

New East Building, CB\#3140, Chapel Hill, NC 27599-3140

David H. Moreau, Chairman, (919) 962-4756, moreau.dcrp@mhs.unc.edu

Phone: (919) 962-3983

FAX: (919) 962-5206

Ohio State University

City \& Regional Planning Program, http://www.crp.ohio-state.edu/crp/wel.htm

Austin E Knowlton School of Architecture, http://www.crp.ohio-state.edu

109 Brown Hall, 190 W. 17th Avenue, Columbus, OH 43210-1320

Burkhard von Rabenau, Ph.D., Head, (614) 292-8279, vonrabenau.1@osu.edu

Phone: (614) 292-1012

FAX: (614) 292-7106

University of Oklahoma

Regional \& City Planning Division, http://www.ou.edu/architecture/drcpl/

College of Architecture, http://www.ou.edu/architecture/

830 Van Vleet Oval, Norman, OK 73019-0263

Christopher Shove, Ph. D., Professor and Director, (405) 325-3871, cshove@ou.edu

Phone: (405) 325-2444

FAX: (405) 325-7558

University of Oregon, Eugene

Department of Planning, Public Policy \& Management, http://utopia.uoregon.edu/academic/grad/crp/crp info.html

School of Architecture \& Allied Arts

Hendricks Hall, Eugene, OR 97403-1209

Michael Hibbard, Director, (541) 346-3897, mhibbard@oregon.uoregon.edu

Phone: (541) 346-3635

FAX: (541) 346-2040

Institute for a Sustainable Environment, http://gladstone.uoregon.edu/ enviro/, Dr. John Baldwin, Director, 130 Hendricks Hall, Phone: (541) 346-3895, Fax: (541) 346-2040, EMail: jbaldwin@oregon.uoregon.edu

University of Pennsylvania

Department of City \& Regional Planning, http://www.upenn.edu/gsfa/cpln, http://www.upenn.edu/gsfa/city plan/html/index/city1.htm

Graduate School of Fine Arts, http://www.upenn.edu/gsfa/index/index.htm

127 Meyerson Hall, Philadelphia, PA 19104-6311

Eugenie L. Birch, Chair, elbirch@pobox.upenn.edu

Phone: (215) 898-8329

FAX: (215) 573-5731

Portland State University

School of Urban Studies \& Planning, http://www.upa.pdx.edu/USP/

College of Urban and Public Affairs, http://www.upa.pdx.edu/index.html

P.O. Box 751, Portland, OR 97207-0751

Sy Adler, Professor and Director, (503) 725-5172, FAX: (503) 725-5199, adlers@pdx.edu

Phone: (503) 725-4045, or (800) 547-8887

FAX: (503) 725-8770

EMail: bradfordc@upa.pdx.edu

Pratt Institute, http://www.pratt.edu/ 
Graduate Center for Planning and the Environment, http://www.pratt.edu/arch/gcpe/index.html

Graduate Architecture and Urban Design, http://www.pratt.edu/arch/urban/index.html

School of Architecture, http://www.pratt.edu/arch/index.html

Higgins Hall, 200 Willoughby Avenue, Brooklyn, NY 11205

Tom Angotti, Chair, (718) 399-4391, tangotti@pratt.edu

Phone: (718) 399-4314

FAX: (718) 399-4332

University of Puerto Rico, http://www.upr.clu.edu/ Graduate School of Planning,

P. O. Box 23354, Rio Piedras Campus, San Juan, PR 00931

Elias R. Gutierrez, Acting Director, (787) 763-7590

Phone: (787) 763-0000, Ext. 5010

FAX: (787) 763-5375

EMail: nvega@rrpac.upr.clu.edu

University of Rhode Island

Department of Community Planning, http://www.uri.edu/cels/cpad home/, cpad@uriacc.uri.edu

College of the Environment and Life Sciences, http://www.uri.edu/cels/

Rodman Hall, 94 West Alumni Avenue, Suite 1, Kingston, RI 02881-0815

Farhad Atash, Ph.D., Chairperson, (401) 874-2982, atash@uriacc.uri.edu

Phone: (401) 874-2248

FAX: (401) 874-5511

Rutgers, State University of New Jersey

Edward J. Bloustein School of Planning and Public Policy, http://policy.rutgers.edu/bloustein/, Civic Square, 33 Livingston Ave, New Brunswick, NJ 08901-1982, (732) 9325475.

Department of Urban Planning and Policy Development, http://policy.rutgers.edu/uppd/, Room 370, (732) 932 3822, Fax: 732.932.2253; Richard K. Brail, Head, (732) 932-3822 Ext. 731, Email: rbrail@rci.rutgers.edu

Department of Urban Studies and Community Health, http://policy.rutgers.edu/usch/, (732) 932 4101, Edward Ortiz, Department Chair, (732) 932-4007, X684.

Rutgers, Center for Urban Policy Research, http://www.policy.rutgers.edu/cupr/index1.htm, Suite 400, (732) 932 3133, Phone: (732) 932-3133, Fax: (732) 932-2363

Department of Public Policy, http://policy.rutgers.edu/dpp/, Suite 202, Phone: (732) 932-2499, Fax: (732) $932-$ 1107, Cliff Zukin, Chair, dppinfo@rci.rutgers.edu.

Center for Land Planning \& Design, http://aesop.rutgers.edu/ landarch/landplan.html, Department of Landscape Architecture, Rutgers, State University of New Jersey, Blake Hall, Cook College, New Brunswick, NJ 08903, Phone: (908) 932-9317, Fax: (908) 932-1940, Steven Strom at strom_c@aesop.rutgers.edu

San Jose State University, http://www.sjsu.edu/

Urban and Regional Planning Department, http://www.sjsu.edu/depts/SocialWork/depts/urbplan/up0d131.htm

College of Social Work

One Washington Square, San Jose, CA 95192-0185

Donald N. Rothblatt, Chair, (408) 924-5867, drothbla@sparta.sjsu.edu

Phone: (408) 924-5882

FAX: (408) 924-5872

University of Southern California

School of Policy, Planning, and Development, http://www.usc.edu/dept/sppd/, supd@usc.edu

Von KleinSmid Center, Los Angeles, CA 90089-0626

Robert Biller, Interim Dean, (213) 740-2264

Phone: (213) 740-6842

FAX: $(213-740-8180$

State University of New York at Buffalo

Department of Planning, http://www.ap.buffalo.edu/planning/, plandept@arch.buffalo.edu

School of Architecture and Planning, http://www.ap.buffalo.edu/

Hayes Hall, 3435 Main Street, Buffalo, NY 14214-3087

G. William Page, Professor and Chairperson, (716) 829-2133 Ext. 109, page@ap.buffalo.edu

Phone: (716) 829-2133

FAX: (716) 829-3256

Cyburbia (formerly called PAIRC - The Planning and Architecture Internet Resource Center), University of Buffalo

School of Architecture, http://www.arch.buffalo.edu/pairc/, Planning Resource Directory,

http://www.arch.buffalo.edu/pairc/planning resource directory.html

University of Tennessee, Knoxville, http://www.utk.edu/

School of Planning, http://planning.cap.utk.edu

College of Architecture and Design, http://www.arch.utk.edu/

1401 Cumberland Avenue, 108 Hoskins Lib., Knoxville, TN 37996-4015

David Patterson, Director, (423) 974-5227

Phone: (423) 074-5227

FAX: (423) 974-5229 
EMail: nloftis@utk.edu

University of Texas at Arlington

City and Regional Planning Program, http://www.uta.edu/supa/cirp.htm

School of Urban and Public Affairs, http://www.uta.edu/supa/

553 University Hall, P.O. Box 19588, Arlington, TX 76019-0588

Robert L. Wegner, Sr., Coordinator, Phone: (817) 272-3366, wegner@uta.edu

Phone: (817) 272-3071

FAX: (817) 272-5008

The University of Texas at Austin

Graduate School in Community and Regional Planning, http://www.ar.utexas.edu/Planning/

School of Architecture \& Planning, http://www.ar.utexas.edu/,

Goldsmith Hall 2.308, Austin, TX 78712-1160

Lawrence W. Speck, Dean, (512) 471-1922, Iwspeck@mail.utexas.edu

Phone: (512) 471-1922

FAX: (512) 471-0716

Texas A\&M University

Department of Landscape Architecture \& Urban Planning, http://taz.tamu.edu/LAUP/

College of Architecture, http://archone.tamu.edu/

Langford 311A, College Station, TX 77843-3137

Jesus H. Hinojosa, Professor and MUP Coordinator, (409) 845-7882, jhh@taz.tamu.edu

Phone: (409) 845-1046

FAX: (409) 862-1784

University of Virginia

Department of Urban \& Environmental Planning, http://urban.arch.virginia.edu/ plan/duep.html, bhh@virginia.edu School of Architecture, http://minerva.acc.Virginia.EDU:80/ arch/

Campbell Hall, Charlottesville, VA 22903

A. Bruce Dotson, Chair, (804) 924-6459, abd8p@virginia.edu

Phone: (804) 924-1339

FAX: (804) 982-2678

Virginia Commonwealth University

Department of Urban Studies \& Planning, http://www.has.vcu.edu/usp/, dusp@vcu.edu

812 West Franklin Street, VCU Box 842008, Richmond, VA 23284-2008

Gary Johnson, Chair, gjohnson@titan.vcu.edu

Phone: (804) 828-2489

FAX: (804) 828-6681

Virginia Polytechnic Institute and State University

Department of Urban Affairs and Planning, http://www.uap.vt.edu/UAPintro.html, uapvt@vt.edu

College of Architecture and Urban Studies, http://www.arch.vt.edu/

200 Architecture Annex, Mail Code 0113, Blacksburg, VA 24061

John Randolph, Ph.D., Professor and Head, (540) 231-6971

Phone: (540) 231-5485

FAX: (540) 231-3367

University of Washington, http://www.washington.edu/

Department of Urban Design and Planning, http://www.caup.washington.edu/html/urbdp/

College of Architecture and Urban Planning, http://www.caup.washington.edu/

Box 355740, 410 Gould Hall, Box 355740, Seattle, WA 98195

Frank V. Westerlund, Interim Chair, (206) 543-2089, fwest@u.washington.edu

Phone: (206) 543-4190

FAX: (206) 685-9597

Wayne State University

Department of Geography \& Urban Planning, http://www.science.wayne.edu/ gup/

College of Urban, Labor \& Metropolitan Affairs

225 State Hall, Detroit, MI 48202

Gary Sands, Associate Professor and Chair, (313) 577-0543, g.sands@wayne.edu

Phone: (313) 577-2701

FAX: (313) 577-0022

University of Wisconsin-Madison

Department of Urban and Regional Planning, http://www.wisc.edu/urpl/

College of Letters and Science and College of Agriculture and Life Sciences

925 Bascom Mall/Old Music Hall, Madison, WI 53706

Stephen M. Born, Professor and Chair, (608) 262-1004

Phone: (608) 262-1004

FAX: (608) 262-9307 
EMail: jaholmes@facstaff.wisc.edu

University of Wisconsin - Milwaukee

Department of Urban Planning

School of Architecture \& Urban Planning, http://www.sarup.uwm.edu/

P. O. Box 413, Milwaukee, WI 53201-0413

Nancy K. Frank, Chair, (414) 229-5372, frankn@uwm.edu

Phone: (414) 229-5563

FAX: (414) 229-6976

Yale University

Planning, Design, and Development of the Urban Landscape

Yale School of Architecture http://www.architecture.yale.edu/default2.html

180 York Street, P. O. Box 208242, New Haven, CT 06520-8242

Phone: (203) 432-2296 


\section{CERL Distribution}

Chief of Engineers

ATTN: CEHEC-IM-LH (2)

ATTN: HECSA Mailroom (2)

ATTN: CECC-R

ATTN: CERD-Z

Engineer Research and Development Center (Libraries)

ATTN: ERDC, Vicksburg, MS

ATTN: Cold Regions Research, Hanover, NH

ATTN: Topographic Engineering Center, Alexandria, VA

Defense Tech Info Center 22304

ATTN: DTIC-O

10

$6 / 00$ 


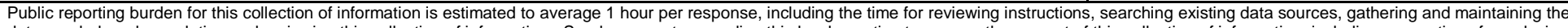

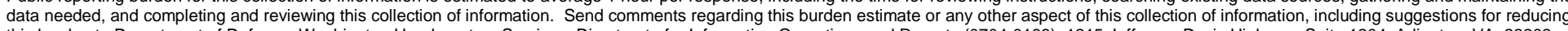

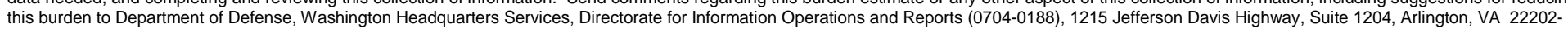

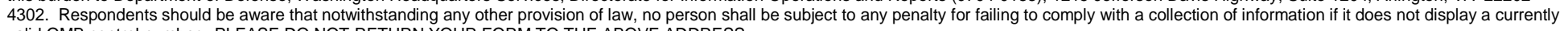
valid OMB control number. PLEASE DO NOT RETURN YOUR FORM TO THE ABOVE ADDRESS.
1. REPORT DATE (DD-MM-YYYY)
2. REPORT TYPE
3. DATES COVERED (From - To)

12-2000

Final

4. TITLE AND SUBTITLE

Scoping Report for a Scenario-Based Planning Protocol for Application in the Regions of Army Installations 5a. CONTRACT NUMBER

5b. GRANT NUMBER

5c. PROGRAM ELEMENT NUMBER

6. AUTHOR(S)

Winifred H. Rose, Robert C. Lozar, and Richard L. Schneider

5d. PROJECT NUMBER

62720A896

5e. TASK NUMBER

5f. WORK UNIT NUMBER

T70, T79

8. PERFORMING ORGANIZATION REPORT

NUMBER

ERDC/CERL TR-00-39

P.O. Box 9005

Champaign, IL 61826-9005

\section{SPONSORING / MONITORING AGENCY NAME(S) AND ADDRESS(ES)}

U.S. Army Corps of Engineers

441 G Street, N.W.

Washington, DC 20314-1000

12. DISTRIBUTION / AVAILABILITY STATEMENT

Approved for public release; distribution is unlimited.

\section{SUPPLEMENTARY NOTES}

Copies are available from the National Technical Information Service, 5285 Port Royal Road, Springfield, VA 22161.

\section{ABSTRACT}

Military installations across the United States are experiencing a number of challenges related to natural resources and natural resource management issues both on and off the installation. Demands of the military mission are often seen as competing or conflicting with the interests of management boards, planning organizations, and other interest groups.

The objective of this work is to describe a regional scenario-based land use planning methodology, and explore how a standardized protocol for comprehensive military land use planning in a regional context could be developed and applied.

This research is to conduct a scoping study that describes regional scenario-based planning methodology, evaluates its potential for application to military land use planning, and presents characteristics and criteria for development of a generalized scenario-based planning protocol adapted for military use.

It is recommended as a result of this scoping study that the Army further pursue development of a less expensive, more efficient, and Army-adapted methodology for applying scenario-based planning to installation and MACOM-level requirements.

15. SUBJECT TERMS

land management, natural resource management, military planning, land use planning, scenario-based planning

\begin{tabular}{|c|c|c|c|c|c|}
\hline 16. SECURITY CL & IFICATION OF: & & $\begin{array}{l}\text { 17. LIMITATION } \\
\text { OF ABSTRACT }\end{array}$ & $\begin{array}{l}\text { 18. NUMBER } \\
\text { OF PAGES }\end{array}$ & $\begin{array}{c}\text { 19a. NAME OF RESPONSIBLE PERSON } \\
\text { Winifred H. Rose }\end{array}$ \\
\hline $\begin{array}{l}\text { a. REPORT } \\
\text { Unclassified }\end{array}$ & $\begin{array}{l}\text { b. ABSTRACT } \\
\text { Unclassified }\end{array}$ & $\begin{array}{l}\text { c. THIS PAGE } \\
\text { Unclassified }\end{array}$ & SAR & 78 & $\begin{array}{l}\text { 19b. TELEPHONE NUMBER (in- } \\
\text { clude area code) } \\
(217) 352-6511 \text {, ext } 6399\end{array}$ \\
\hline
\end{tabular}

